\title{
Residual Stress Measurements in Extreme Environments for Hazardous, Layered Specimens
}

\author{
B. C. Benefiel ${ }^{1}$ - E. D. Larsen ${ }^{1}$ - M. B. Prime ${ }^{2}$ (1) $\cdot$ A. M. Phillips ${ }^{1} \cdot$ K. B. Davies ${ }^{1} \cdot$ D. Castano ${ }^{2} \cdot$ J. I. Cole $^{1}$
}

Received: 4 August 2021 / Accepted: 12 December 2021 / Published online: 4 January 2022

(c) The Author(s) 2022

\begin{abstract}
Background In nuclear fuel plates of low-enriched U-10Mo (LEU) clad with aluminum by hot isostatic pressing (HIP), post-irradiation stresses arising during reactor shutdown are a major concern for safe reactor operations. Measurement of those residual stresses has not previously been possible because the high radioactivity of the plates requires handling only by remote manipulation in a hot cell.

Objective The incremental slitting method for measuring through-thickness stress profiles was modified, and a system for automated, remote operation was built and tested.

Methods Experimental modifications consisted of replacing electric-discharge machining (EDM) with a small end mill and strain-gauge measurements with cantilever displacement measurements. The inverse method used to calculate stresses was the pulse-regularization method modified to allow discontinuities across material interfaces. The new system was validated by comparing with conventional slitting on a depleted U-10Mo (DU) fuel plate.

Results The new system was applied to two measurements each on six as-fabricated (pre-irradiation) LEU miniature fuel plates. Variations between the measurements at two locations in the same plate were strongly correlated with measured geometrical heterogeneity in the plate-a tilt in the fuel foil. Compressive stresses in the U-10Mo were shown to increase from 20 to $250 \mathrm{MPa}$ as the ratio of aluminum thickness to U-10Mo thickness increased causing increased constraint during cooling. Faster cooling rates during processing also increased stress magnitudes.

Conclusions The measurements trends agreed with data in the literature from similar plates made with DU, which further validates the method. Because other methods are impractical in a hot cell, the modified slitting method is now poised for the first measurements of post-irradiation stresses.
\end{abstract}

Keywords Residual stress measurement $\cdot$ Nuclear fuel $\cdot$ Low-enriched uranium $\cdot$ Hot cell $\cdot$ Incremental slitting

\section{Introduction}

\section{Motivation}

The U.S. High Performance Research Reactor Project is pursuing development and qualification of a new high-density monolithic fuel to facilitate conversions of high performance nuclear reactors from the use of high-enriched uranium (HEU) to low-enriched U-10Mo (LEU) in order to meet

M. B. Prime

prime@lanl.gov

1 Idaho National Laboratory, Idaho Falls, ID 83415, USA

2 Los Alamos National Laboratory, Los Alamos, NM 87545, USA
U.S. non-proliferation policy objectives. Four higher-power test reactors (the Advanced Test Reactor, National Institute of Standards and Technology Research Reactor, Massachusetts Institute of Technology Reactor, and the Missouri University Research Reactor) and one critical facility (the Advanced Test Reactor-Critical) are targeted for conversion to a monolithic plate-type fuel system. The fuel system consists of a U-10Mo alloy LEU fuel foil that has thin $\mathrm{Zr}$ diffusion-barrier interlayers co-rolled to the top and bottom surfaces of the foil and clad in aluminum alloy (AA) 6061 by hot isostatic pressing (HIP) [1]. To support fabrication development and fuel-performance evaluations, new testing and analysis capabilities are being developed to evaluate the properties of fuel specimens, both in their as-fabricated and irradiated conditions. 
Fig. 1 Fuel plates have a U-10Mo foil HIP'd inside an aluminum cladding

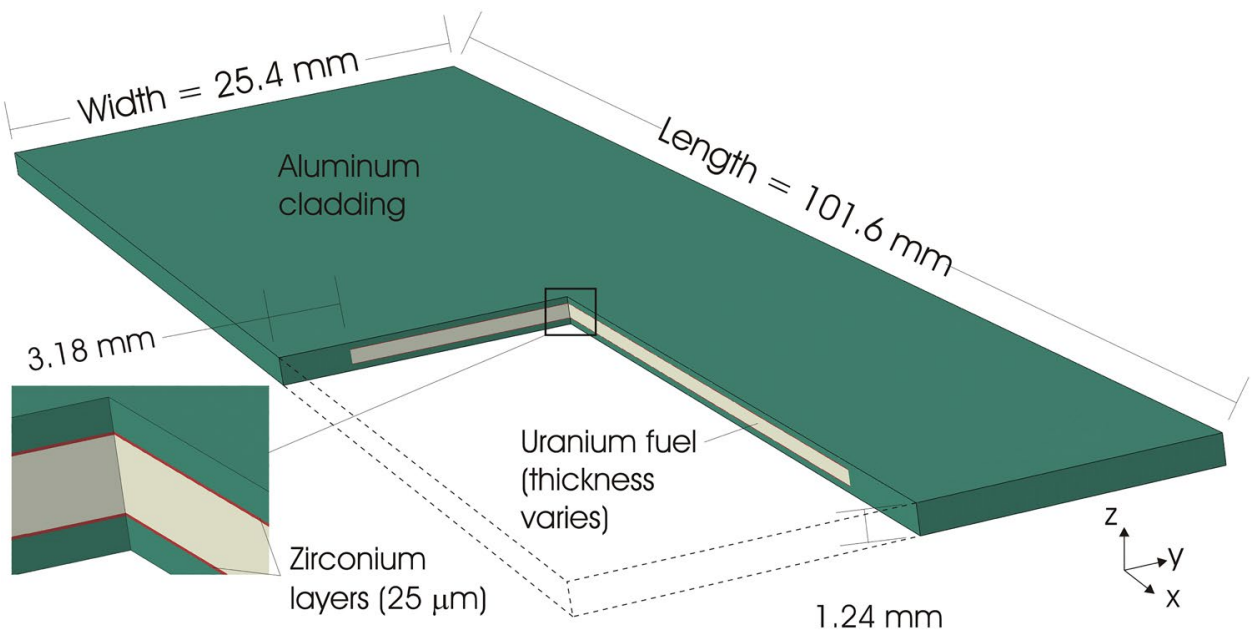

$1.24 \mathrm{~mm}$
Monolithic plate-type fuel is a layered metallic composite of metals with different mechanical and thermal properties and constrained interfaces created during the HIPbonding process. Residual stresses develop in the layers during cooling from the HIP-processing temperature and again during cooling after reactor shutdown [2, 3]. The stresses can contribute to fuel cracking, plate breaching, blistering, or delamination. Among several primary requirements for fuel qualification is to demonstrate the fuel plate's ability to resist delamination to prevent the release of fission products and maintain high thermal conductivity for heat transfer. Fuel-performance modeling results, taking into account irradiation-induced fuel creep, suggest preirradiation residual stresses in the U-10Mo fuel material do not significantly influence irradiation performance as these stresses are relaxed very quickly during initial irradiation [4]. However, post-irradiation residual stresses developed during reactor shutdown are believed to play an important role in possible fuel failures at high burnup [3]. Pillowing, also known as blistering, was observed in mini-plates tested in the Advanced Test Reactor to very high fission densities. Several of these plates pillowed at a plate-average fission density of approximately $8 \times 10^{21}$ fissions $/ \mathrm{cm}^{3}$ with a peak fission density approaching $1.2 \times 10^{22}$ fissions $/ \mathrm{cm}^{3}$ [5]. Note the pillowing in the tested HEU plates is not directly representative of the LEU fuel application because the LEU fuel is unable to reach the same fission density levels as HEU. Nonetheless, the knowledge of the residual stresses is key for defining operational limits for the LEU fuel.

While post-irradiation stresses from modeling is available, these simulations must be validated experimentally. Accurately modeling radiation-induced creep [6], radiation-induced swelling [7], and other non-linear material behaviors is challenging, especially since properties change during irradiation. Therefore, it is desired to measure the post-irradiation residual stresses to support validation of the fuel-performance models.
Residual stress measurements are challenging even under ideal conditions with non-hazardous samples [8, 9]. Residual stresses have been mapped in as-manufactured plates with depleted U-10Mo (DU) foil surrogates with high spatial resolution techniques like synchrotron X-ray diffraction [10], as well as with lower spatial resolution techniques such as neutron diffraction $[11,12]$. However, measurements in LEU fuel, especially after irradiation, is currently not permitted in such facilities. In this project, residual-stress measurement techniques appropriate for remote handling operations with both fresh and irradiated LEU fuel plates were developed and evaluated for use. To prove the technique prior to application to irradiated plates, this work presents two measurements each on six as-fabricated (pre-irradiation) LEU miniature fuel plates.

\section{Measurement Constraints and Method Selection}

Measuring residual stress can be challenging [9, 13], but the application in this work presents an unusual set of constraints that limits the measurement possibilities. The first constraint comes from the monolithic fuel mini-plate geometry, shown as a schematic in Fig. 1, and the location of interest. Because of the debonding concern, the stresses to be measured are the subsurface stresses in both the U-10Mo and aluminum local to the interface. Therefore, surface measurement techniques like X-ray diffraction are not appropriate. With some U-10Mo foils only $0.25 \mathrm{~mm}$ thick, the typical $\sim 0.5-\mathrm{mm}$ resolution of neutron diffraction [14] would be insufficient to resolve the relevant stress gradients near the interface. Other less common measurement techniques are similarly limited in their ability to measure the local, subsurface stresses [9].

The more restrictive and less common constraints come from the high radiological hazards of handling specimens after use in a reactor. Such specimens can only be measured in a hot cell using remote manipulation, as shown in Fig. 2. 


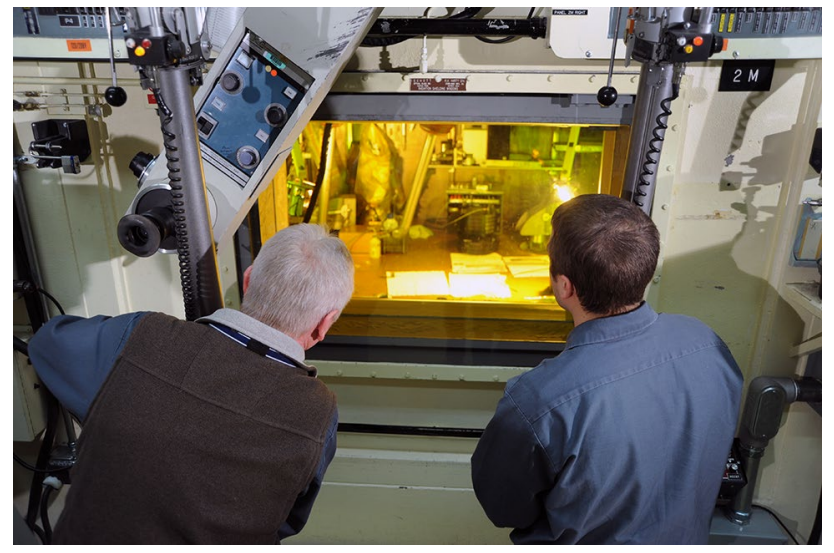

Fig. 2 Measurements in a radiation hot cell require remote handling from operators outside the cell using manipulators. This setup limits experimental techniques

This currently precludes measurement in a neutron or synchrotron diffraction facility or any other specialty facility. A laboratory X-ray diffraction system, which could fit in a hot cell, can sometimes be used to measure a high-resolution depth profile of stresses subsurface if incremental electropolishing is used to remove surface layers and expose deeper material [15]. However, the use of an acid and creation of liquid radioactive waste in a hot cell is problematic and would only be considered as a last resort.

Additional constraints in a hot cell include several issues relevant to the fuel plate measurement system. All handling and operations must be compatible with model-J manual master/slave manipulators [16]. A tabletop design is required for operation on a standard worktable. Modularity is required for planned maintenance or component replacement. Equipment should remain operational with an accumulated gamma dose of $10^{7} \mathrm{rad}$, although component replacement is possible with the modular design if it can be accomplished with the manipulators.

Considering all the constraints, the incremental slitting method $[17,18]$ and the incremental hole-drilling method [19] were the best candidates for measuring the subsurface stresses in the fuel plates. However, the remote manipulation constraint in a hot cell precludes mounting strain gauges, which is the conventional instrumentation used for both methods. With parts-per-million sensitivity, strain gauges are difficult to match with other technology. Also, wire electric discharge machining, the preferred machining method for slitting [20], was not feasible in the hot cell.

Alternative hot-cell appropriate approaches for both methods were tested on surrogate fuel plates [21, 22]. For the slitting method, a small end mill was used to make a slit at one end of the plate, where the plate was clamped. Instead of strains, displacement was measured at the far end of the beam. These changes are described in more detail later. The

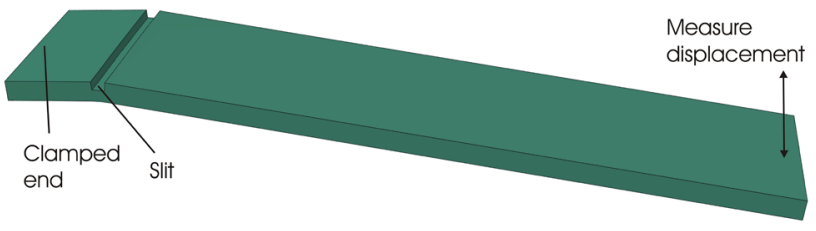

Fig. 3 A cantilever slitting configuration was used to achieve sensitive displacement measurements

hole-drilling measurements used non-contact electronic speckle pattern interferometry (ESPI) to replace a strain gauge and measure deformations around the hole [23, 24]. Both methods performed adequately in surrogate testing.

Slitting was chosen over ESPI hole drilling for largely practical considerations. Because it measures stresses local to the hole, the hole-drilling method is capable of better spatial resolution by potentially using multiple holes to measure $\sigma_{x}(z), \sigma_{y}(z)$, and $\tau_{x y}(z)$ at different $(x, y)$ locations (coordinates are defined in Fig. 1). The slitting method can only measure $\sigma_{x}(z)$ at different $x$ locations. Unfortunately, ESPI would require significantly more engineering to feedthrough the laser optics. The detectors would not survive the radiation environment for long and would either have to be replaced periodically (which is expensive) or used through a viewing port (loss of sensitivity). Hole drilling also has less sensitivity as the hole depth increases, which includes the region of interest near the cladding-foil interface. Therefore, slitting was chosen as the simpler option with less technical risk. At least in more ideal conditions, slitting gives very high spatial resolution stress profiles [25-31] with excellent repeatability [32].

\section{Methods and Design}

Figure 3 shows the cantilever slitting configuration that was developed to satisfy the operational constraints and to mitigate the loss of sensitivity because of the inability to use strain gauges. The slit is cut close to the fixed cantilever end using a small end mill. Non-contact sensors measure the displacement at the free end of the cantilever. From simple geometry of the cantilever deflection, the displacement for a given stress scales linearly with the distance from the slit to the measurement. Therefore, using this long cantilever arrangement effectively amplifies the measurement signal and improves sensitivity. Note because strains from hole drilling are local to the hole and cause no significant deformations farther away, such an arrangement for hole drilling is not feasible. It is the full width (y-direction) slit that allows the hinge deformation mode illustrated in Fig. 3 and the resulting large deformations. Although Fig. 3 shows the plate oriented with the bottom face down, the actual plates 
are oriented with the long edge down and the slit aligned vertically so that gravity does not artificially add to the deformations.

The rest of this section details the implementation of this configuration for testing in a hot cell. First, we discuss the two main functional elements: making the slit and measuring the deflection. Next, we discuss the full system to permit remote handling operation in a hot cell. The hot-cell design attempts to achieve the same goals as standard slitting procedure [33], but the details are different.

\section{Machining and Measurement Hardware}

\section{Displacement Measurement}

Measurement of the fuel plate's deflection is performed by Micro Epsilon eddyNCDT 3300 eddy-current system with the ES2 sensors. These sensors are relatively simple, precise, non-contact, and can function reliably in the radiation environment. The sensors have a measurement range of $0-2 \mathrm{~mm}$ and a resolution of $1.0 \mu \mathrm{m}$. Scoping calculations indicated that $1.0 \mu \mathrm{m}$ allowed for overall measurement uncertainty similar to using strain gauges. It is possible the deflections could exceed the $2 \mathrm{~mm}$ measurement range during an experiment. The sensors are positioned using motion-control axes and can be moved between cuts to accommodate large deflections. Because the sensor is measuring during such re-positioning, correcting the data for the motion is simple and accurate. Two sensors are used on opposite faces of the specimen for redundancy of the measurement.

\section{End Mill Slitting}

An end mill was chosen for the cutting because they were widely used for the slitting method prior to the advent of wire EDM [34, 35]. Our slitting end mill is powered by a Nakanishi E3000 high-speed motor that can be operated without cooling air up to $25,000 \mathrm{rpm}$. The difference in material properties between the HIP-softened aluminum, which has properties more like the -O temper "soft anneal" than the precipitation hardened -T651 [36], and the much harder U-10Mo complicated the choice of end-mill design, cutting speed (controlled by the spindle RPM), feed rate, and depth of cut. Also, the ideal depth of cut of an end mill, about $1 / 5$ of the tool diameter, would give much too coarse depth resolution of the stress profile [37]. Therefore, the cut depth was well below optimal for the end mill. Multiple tests were performed to evaluate different cutting parameters. Because the interface locations are not known precisely enough nor are they necessarily coincident with the cut path, it was considered impractical to change parameters during the test to optimize for each material. Therefore, the final

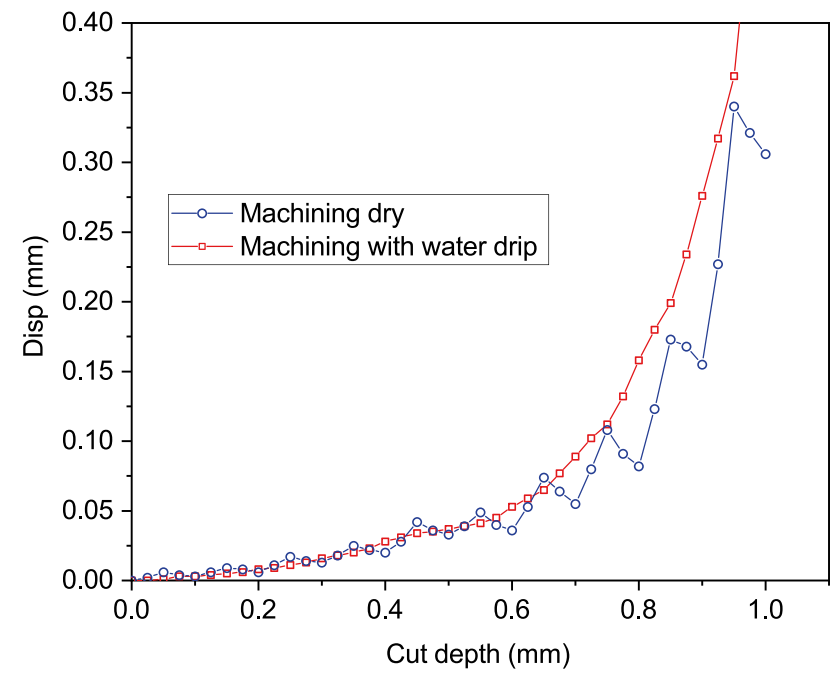

Fig. 4 Adding a water drip reduced machining-induced oscillations at least partially caused by dry machining with the end mill. Data from a test performed on annealed 6061 aluminum. Ignoring the oscillations, the displacements are consistent with modest residual stresses in the aluminum

parameters were a compromise between the ideal cutting parameters for the aluminum and for the U-10Mo.

Early testing revealed an issue that required a design change. Initial test cutting had been performed dry because the preferred design for hot-cell operations would not generate any liquid waste. Dry machining of the soft aluminum resulted in end displacement vs. depth data that showed oscillations with periodicity of about $100 \mu \mathrm{m}$ or less, see Fig. 4. Macrostress oscillations at that length scale are not plausible in these samples, and this setup will not resolve microstress effects because the slit, at 25-mm long in the $y$-direction, averages over thousands of grains. Therefore, the oscillations must have been caused by cutting artifacts. Figure 4 shows that adding a water drip onto the cutting region helped minimize the oscillations. In the final hotcell implementation, a water-soluble cutting fluid was used, and increasing the cut depth from $25 \mu \mathrm{m}$ to $50 \mu \mathrm{m}$ also helped reduce oscillations. However, the oscillations were not always completely eliminated. For the final tests in this study, we used a $0.79 \mathrm{~mm}$ diameter, 4-flute end mill with $0.1 \mathrm{~mm}$ radius on the cutters at 18,000 RPM with a $2 \mathrm{~mm} /$ sec feed rate. This setup, although the best compromise, still had difficulties cutting the U-10Mo deeply, so reliable data was not possible after about halfway through the thickness of the U-10Mo. The resulting cut width in both materials was not noticeably larger than the $0.79 \mathrm{~mm}$ mill diameter.

\section{System}

Figure 5 shows the general tabletop layout for the measurement system. The machining hardware consists of six 
Fig. 5 The machining and displacement measurement sensors are positioned using six motion-control axes all mounted on an aluminum baseplate

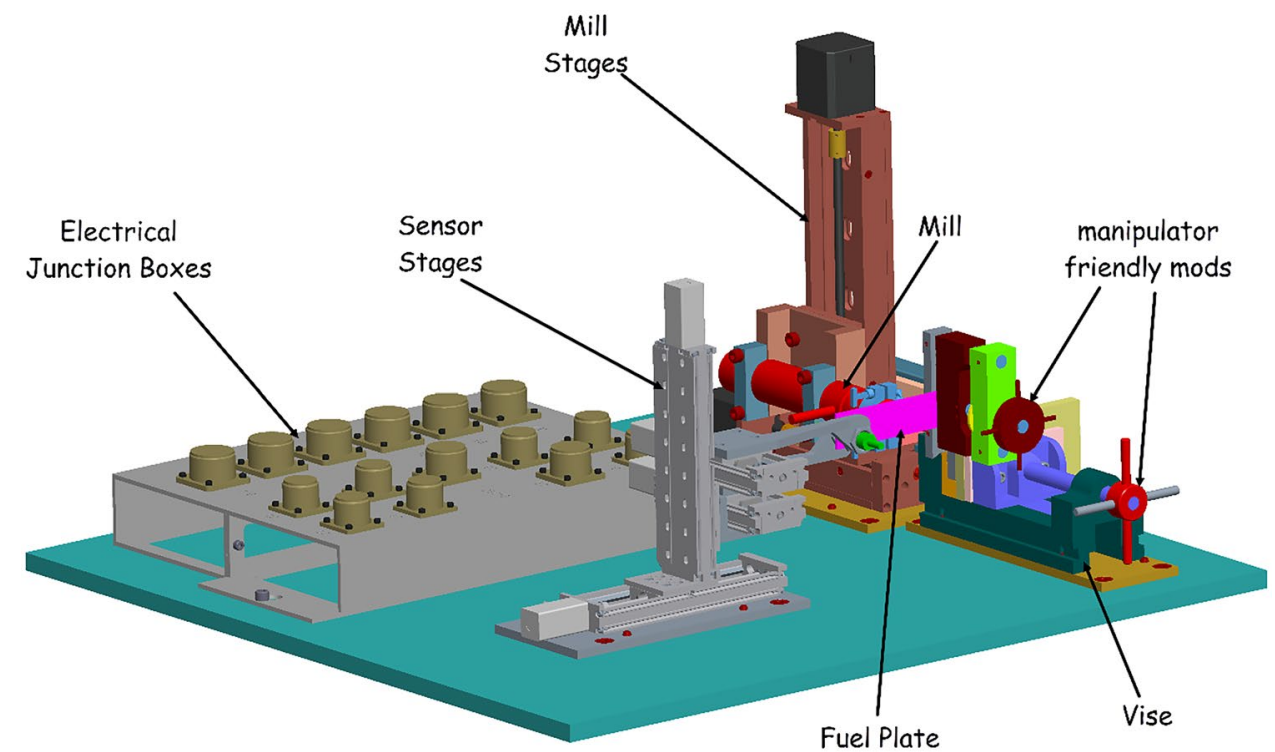

Fuel Plate motion-control axes which position the milling motor and displacement sensors. Each of these axes can be controlled independently by the operator but are programmed to work in a coordinated manner with minimal operator interaction. Two axes are used to position the milling motor, and four control the position of the displacement sensors. The other major components are the clamping mechanism, displacement sensors, and mill motor. The in-cell components are mounted on an aluminum baseplate measuring $0.6 \mathrm{~m} \times 0.6 \mathrm{~m}$. The baseplate and components are easily moved during idle periods to storage in low-level radiation areas to prevent unnecessary degradation of the system.

Linear ball-screw slides driven by stepper motors provide the axis motion control. Each axis can be positioned with $50 \mu \mathrm{m}$ accuracy and $1 \mu \mathrm{m}$ repeatability and is controlled remotely. Additionally, because the horizontal machine tool axis is critical to ensure the accurate cutting depth, it is equipped with a magnetic encoder to increase its positioning accuracy to $5 \mu \mathrm{m}$.

\section{Measurement Operations}

There are five main steps that need to be performed by the operator to control the system. During normal operation, the steps are preformed sequentially, and the system will prevent the operator from performing a step out of sequence. These steps are homing, surface mapping, sensor positioning, sensor calibration, and machining. Homing is done initially during the system start to position the linear axes to a known position indicated by Hall Effect home switches embedded in the axes.

The next step is not standard for slitting but is necesary to account for the curved surfaces of the plate. At the cut location, the surface height of the plate is mapped relative to the end mill. This mapping is accomplished by imposing a 5-V signal onto the end mill bit and grounding the fuel plate to the clamping system. The end mill tool is touched to the fuel plate incrementally along the vertical surface of the plate. As the tool touches the surface of the plate, a signal is detected and that position is recorded. A thin oxide layer, which can prevent electrical contact, may be on the surface of the plate, so the end mill is spinning during the operation to penetrate the oxide later into the conductive metal below. Care is taken by the controller software to limit the force of the contact to avoid marring of the fuel plate surface. Later, during slit machining for the stress measurement, the surface contour is followed by the end mill axes to get a uniform cut depth.

After surface mapping, the displacement sensors are moved into position at the end of the plate, so they are ready to measure the plate deflection during slitting. Typically, the sensors are positioned vertically at the center of the plate at an operator-defined distance from the clamp. They are positioned as close as possible to the end of the fuel plate to maximize the measured deflection of the plate. Based on experience on surrogate plates, in this study they were positioned $0.5 \mathrm{~mm}$ from the surface of the plate on the drill side and $1.5 \mathrm{~mm}$ from the surface on the far side, which usually allowed the test to be completed without needing to reposition the sensors. Figure 6 shows a close-up photograph of the sensors in place.

The eddy-current sensors are calibrated at the factory for nonferrous metals, but variations in materials can still cause errors on the displacement reading. Therefore, the sensors go through a three-point calibration by the operator to maximize accuracy of the reading. The sensor calibration step starts with positioning the sensor $0.2 \mathrm{~mm}$ from the surface based on the factory calibration. The translation stages then position the sensors at $1.2 \mathrm{~mm}$ and then $2.2 \mathrm{~mm}$ from the 


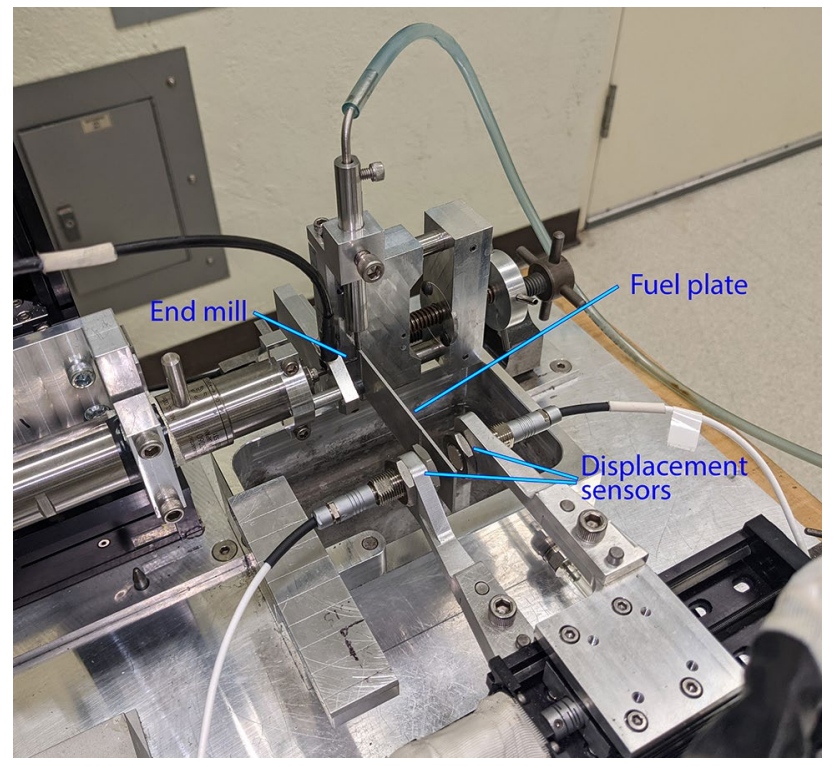

Fig. 6 Redundant eddy-current sensors are used on opposite faces of the fuel plate to measure displacement

surface. The relative displacements measured by the sensors are used by the sensor controllers to calibrate the sensors. A calibration-verification step is then performed to verify the calibration of the sensors.

After starting the machining operation, the system will run automatically without any input from the operator. The system will machine a slit to the programmed depth following the surface height map generated during the surface mapping, then measure the deflection of the plate. During the deflection measurement, the end mill is retracted and shut off to prevent it from causing any vibration of the fuel plate. The system records the eddy-current sensor data, then automatically proceeds to the next machining pass.

\section{As-Built Geometry Via Ultrasound}

To analyze the residual stress data, it is necessary to know the thicknesses of each layer and the locations of the interfaces. That information is available prior to residual stress measurements from minimum cladding (min-clad) ultrasonic thickness testing done to ensure that the thickness safety criterion is met to decrease the likelihood of a cladding breach in reactor operation [38]. A min-clad scan uses a pulse-echo technique employing high-frequency transducers, not only to detect different interfaces within the plate, but also to determine the thickness of that interface. Taking into consideration the speed of sound in a given material, gates are set up on the ultrasonic scan that allow the slicing of material into images representing $25 \mu \mathrm{m}$ of depth for each image. By examining the images, the location of layer interfaces can be determined along the plate to within $25 \mu \mathrm{m}$ resolution.
This ultrasonic testing showed that the fuel foil is generally not perfectly in plane with the outer cladding surface of the mini-plate. Rather, it is tilted. Effectively, the cladding thickness is not uniform along the length of the plate. This will be illustrated later.

\section{Analysis Methods}

Because the residual stresses rearrange after each increment of slit depth, one must solve an elastic inverse problem in order to determine the original residual stress versus depth profile [17]. Many methods have been used for solving the inverse problem. In selecting a method, the key consideration for the application in this work was the possibility for a discontinuity in the stress profile as the interfaces between materials are crossed. Typical methods for solving the inverse problem enforce some smoothing to handle noise in the strain data, but here the discontinuity should not be smoothed. Various inverse methods have been used to allow for discontinuities across layers with this type of inverse problem [39-43]. We chose the pulse-regularization method [44], which handles noisy data robustly and can handle a discontinuity with a simple adaptation.

It is not possible to resolve the stress in the zirconium. The interface locations in the fuel plates are determined by ultrasound measurements to a precision of about $25 \mu \mathrm{m}$ [45]. Since the $\mathrm{Zr}$ layers are nominally just $25 \mu \mathrm{m}$ thick, the location uncertainty encompasses the full layer thickness. Furthermore, since the cut increments are $50 \mu \mathrm{m}$, there is no cut increment that only releases stresses in the $\mathrm{Zr}$. So even if we knew exactly where the layer was, we would not resolve the stresses in the Zr. Neutron-diffraction measurement of average stresses in the $\mathrm{Zr}$ indicate the stresses are quite similar to those in the U-10Mo [11, 12].

\section{Pulse-regularization with Allowance for Discontinuities}

The pulse-regularization methodology for layers from [41, 46] is reviewed, starting with the traditional pulse-regularization method [44] before moving onto the formulation that allows for discontinuities. Before adding regularization, the pulse method is equivalent to the "integral method," historically used for hole drilling [47]. Prior to inverting the equation to solve for stress, the pulse method is given in equation form by

$\mathbf{G} \boldsymbol{\sigma}=\mathbf{d}$

where $\mathbf{d}$ is a column vector of the strains or displacements measured at each slit depth, and $\boldsymbol{\sigma}$ is a column vector of the (unknown) average stresses originally present over each increment of slit depth. $\mathbf{G}$ is a lower triangular matrix of the coefficients relating those stresses, as illustrated in Fig. 7, to the measured strains. 


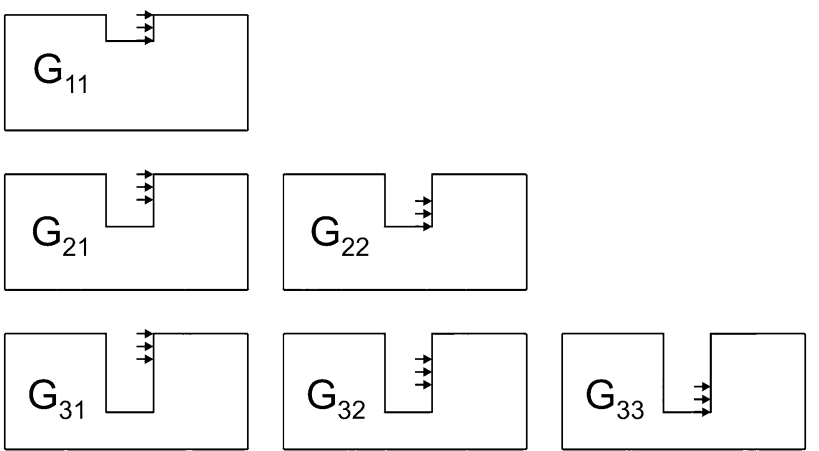

Fig. 7 The coefficients $\mathrm{G}_{\mathrm{ij}}$ correspond to the contribution of the stress over depth increment $j$ to the strains measured at slit depth $i$. Stresses are applied to opposing faces (only one shown, for clarity). Adapted from [44]

To maximize spatial resolution, the number of stresses is taken as equal to the number of measured strains (i.e., the number of cut depths). Solving for the stresses directly from eq. (1) is possible but generally results in a noisy solution. Tikhonov regularization smooths the stress solution by applying a penalty function to some measure of noise in the calculated stress profile [44]. It reduces the adverse effect of noise without significantly altering the part of the stress solution corresponding to the "true stresses." To implement Tikhonov regularization, eq. (1) is pre-multiplied by $\mathbf{G}^{\mathbf{T}}$ and augmented by the penalty term. The result is:

$\left(\mathbf{G}^{\mathbf{T}} \mathbf{G}+\beta \mathbf{C}^{\mathbf{T}} \mathbf{S}^{\mathbf{T}} \mathbf{H S C}\right) \boldsymbol{\sigma}=\mathbf{G}^{\mathbf{T}} \mathbf{d}$

where the regularization comes from the matrix $\mathbf{C}$ which numerically approximates the second derivative of the stress profile. For uniformly spaced data, ${ }^{1}$ the matrix product $\mathbf{H} \mathbf{S}$ $\mathbf{C}$ has the following structure (for simplicity, illustrated for four cut increments):

$$
\text { HSC }=\left[\begin{array}{ccccc}
\left(h_{1}-h_{0}\right) / W & \left(h_{2}-h_{1}\right) / W & \left(h_{3}-h_{2}\right) / W \\
& \left(h_{4}-h_{3}\right) / W
\end{array}\right]\left[\begin{array}{ccccc}
s_{1} & & & \\
& s_{2} & \\
& & \\
& & s_{3} & \\
& & s_{4}
\end{array}\right]\left[\begin{array}{cccc}
0 & 0 & 0 & 0 \\
-1 & 2 & -1 & 0 \\
0 & -1 & 2 & -1 \\
0 & 0 & 0 & 0
\end{array}\right]
$$

where the first and last rows of $\mathbf{C}$ are set to zero to eliminate the degenerate regularization that an "incomplete" (-1 $2-1)$ pattern would produce at the end points. $W$ is the part thickness in the cutting direction, $h_{i}$ is the slit depth at increment $i$ and matrix $\mathbf{S}$ in eqs. (2) and (3) contains along its main diagonal the standard errors $\mathrm{s}_{\mathrm{i}}$ in the deformation data $d_{\mathrm{i}}$. In this work, the standard errors are equal for all the data so $\mathbf{S}$ is taken as the identity matrix.

\footnotetext{
${ }^{1}$ See [44] for general formulas for unevenly spaced intervals.
}

In eq. (2), $\beta$ is the regularization parameter. $\beta=0$ gives no regularization, and $\beta>0$ increases the amount of regularization. Equation (2) can be solved for stress using simple matrix algebra.

Adapting the regularization approach to allow for discontinuities at known locations simply requires removing select rows in the $\mathbf{C}$ matrix. For a discontinuity that is exactly at the interface between two depth increments, there are two rows in $\mathbf{C}$ that act to smooth across the interface that should be removed. An example of such a modified matrix for an example with eight cut increments and the material interface between the 4th and 5 th slit depth is given by:

$\mathbf{C}=\left[\begin{array}{cccc|cccc}0 & 0 & 0 & 0 & 0 & 0 & 0 & 0 \\ -1 & 2 & -1 & 0 & 0 & 0 & 0 & 0 \\ 0 & -1 & 2 & -1 & 0 & 0 & 0 & 0 \\ 0 & 0 & 0 & 0 & 0 & 0 & 0 & 0 \\ 0 & 0 & 0 & 0 & 0 & 0 & 0 & 0 \\ 0 & 0 & 0 & 0 & -1 & 2 & -1 & 0 \\ 0 & 0 & 0 & 0 & 0 & -1 & 2 & -1 \\ 0 & 0 & 0 & 0 & 0 & 0 & 0 & 0\end{array}\right], \boldsymbol{\sigma}=\left\{\begin{array}{c}\sigma_{1}^{A} \\ \sigma_{2}^{A} \\ \sigma_{3}^{A} \\ \sigma_{4}^{A} \\ \hline \sigma_{5}^{B} \\ \sigma_{6}^{B} \\ \sigma_{7}^{B} \\ \sigma_{8}^{B}\end{array}\right\}$

where $\sigma_{i}^{A}$, refers to the stress over depth increment $i$ where that increment is in material $\mathrm{A}$ as compared to material $\mathrm{B}$. For visual illustration, lines are shown in eq. (4) to indicate the material interface where a stress discontinuity is allowed. Observe none of the (-1 2 -1) patterns in $\mathbf{C}$ cross the interface to avoid any smoothing of the discontinuity.

Further pairs of rows can be removed for additional interfaces. If a material interface is within a cut increment, discontinuities should be allowed on either side of the stress for that increment by zeroing three rows of $\mathbf{C}$. If the location of an interface is not known with sufficient precision, more rows may need to be removed to ensure the discontinuity is resolved.

Selecting the amount of regularization and calculating

uncertainties is challenging for data analysis that uses an inverse solution and has been studied recently [48-51]. Because the work here uses displacements instead of strains and allows for stress discontinuities, none of the previous methods were precisely applicable. After trial and error, an adaptation of the Olson method for incremental hole drilling [50] proved to be the most robust approach. The amount of regularization was chosen by varying the regularization parameter $\beta$ over more than 10 orders of magnitude. As $\beta$ increases, the root-mean-square misfit between the measured displacements and those given by inverse solution increases 


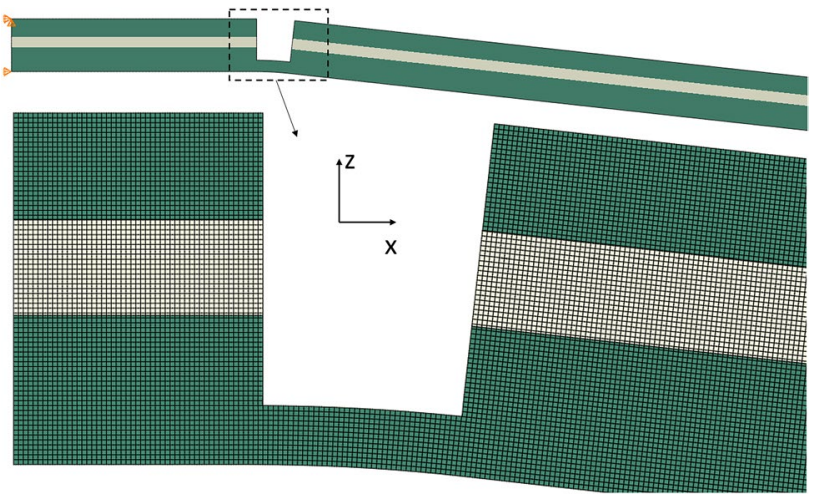

Fig. 8 A 2D plane-strain, elastic finite-element model is used to provide calibration coefficients

and eventually plateaus. The $\beta$ value that gives a misfit of $80 \%$ of the plateau value is chosen.

Uncertainties in the stresses are then calculated based on both uncertainty in the measured displacements and in $\beta$ [49]. Displacement errors were assumed to be $2 \mu \mathrm{m}$, larger than the sensor resolution, because of the data oscillations like those in the water drip trial in Fig. 4. Those errors are propagated through the inverse solution to get stress uncertainties [48]. Uncertainty in $\beta$, regularization uncertainty, is a "model error" associated with the inverse solution and is a significant source of uncertainty [48]. The regularization uncertainty was calculated by varying $\beta$ plus and minus two orders of magnitude from the chosen value and calculating the standard deviation in the stresses at every point [50]. The two uncertainty sources are combined in quadrature at every point in the stress profile to give the total uncertainty.

\section{FEM for Coefficients}

As is standard with the slitting method $[52,53]$, the coefficients in $\mathrm{G}$ are calculated using a series of elastic finiteelement method (FEM) analyses equivalent to Fig. 7. The $\mathrm{Zr}$ layers are not included in the elastic finite-element calculations of the calibration coefficients and are lumped in with the $\mathrm{Al}$ cladding. This approximation is partly motivated by the imprecise knowledge of the location of the layers. However, the approximation causes no significant uncertainty or error. The cantilever deformations in the mini-plate, like any composite beam, are largely controlled by the elastic properties of the outermost layers. In an extreme example to check the effect, calculations for a composite Al-LEUAl beam were compared with calculations where the entire LEU layer was replaced with $\mathrm{Al}$, making a monolithic beam. The differences were small. Further calculations adding in $\mathrm{Zr}$ layers to the composite beam resulted in only insignificant differences.
The 2D plane-strain model that represents an $\mathrm{x}-\mathrm{z}$ cross section (see Fig. 1) along the mid-width of a fuel plate is shown in Fig. 8. This analysis assumes the residual stresses at the $\mathrm{x}$ location of the slot vary only in the $\mathrm{z}$ direction and are constant across the width (y) direction, that is $\sigma_{x}$ at this $\mathrm{x}$ location $=\sigma_{x}(z)$. A correction for variations in stress and material in the y-direction will be discussed next. For the 2D FEM calculations, using plane strain is accurate because these specimens are so much wider than they are thick [54]. The calculations use isotropic elastic moduli of $69 \mathrm{GPa}$ and $90 \mathrm{GPa}$ and Poisson's ratios of 0.33 and 0.35 for the $\mathrm{Al}$ and U-10Mo, respectively. Some elastic anisotropy in the U-10Mo could be expected because of texture from the rolling, but neutron diffraction studies showed isotropy in the rolling plane [55], which is the relevant stiffness for slitting. We used values consistent with the neutron diffraction analysis and also modeling [10].

The analysis must model all $n$ slit depths, and at the $i$ th slit depth must calculate a coefficient for $i$ pulse loads making for $n *(n-1) / 2$ calculations. In this work, the Abaqus software [56] was used along with the Python scripting interface, which allows for automation of the multiple calculations.

\section{D Correction}

The 2D model assumes the geometry and the stresses are uniform in the out-of-plane y-direction. Yet, stress variations across the width of the specimen can have a significant effect on the stresses measured by slitting [57]. Figure 1 shows that in the actual 25.4-mm wide mini-plate, the U-10Mo fuel is surrounded by $3.2 \mathrm{~mm}$ of aluminum on either side, making the width $3 / 4 \mathrm{U}-10 \mathrm{Mo}$ and $1 / 4$ aluminum. After cooling from the HIP-bonding temperature, the difference in thermal expansion is expected to leave the U-10Mo mostly in compression and the aluminum in tension. So at a given cut depth that reaches the U-10Mo, the analysis would assume a uniform stress in the out-of-plane direction but only $3 / 4$ would actually be in compression while the other $1 / 4$ might be in tension. The data analysis cannot solve for a non-uniform stress in the y-direction and will instead give an average stress. Although some attempts have been made to measure such variations [58] with slitting, the results are limited by a non-unique inversion.

Measurement of an average stress is not suitable for the intended uses of the measurement results, which include comparing with a process model or using stress magnitudes to help assess the propensity for debonding. Therefore, we consider any result other than the local stresses in the $\mathrm{U}-10 \mathrm{Mo}$ to be an error. In this section, the error from this 3D effect was estimated using a 3D finite-element model that has the full geometry but omits the $\mathrm{Zr}$ layers for simplicity. A realistic residual stress field that includes the 3D effects was introduced by making some reasonable assumptions, 


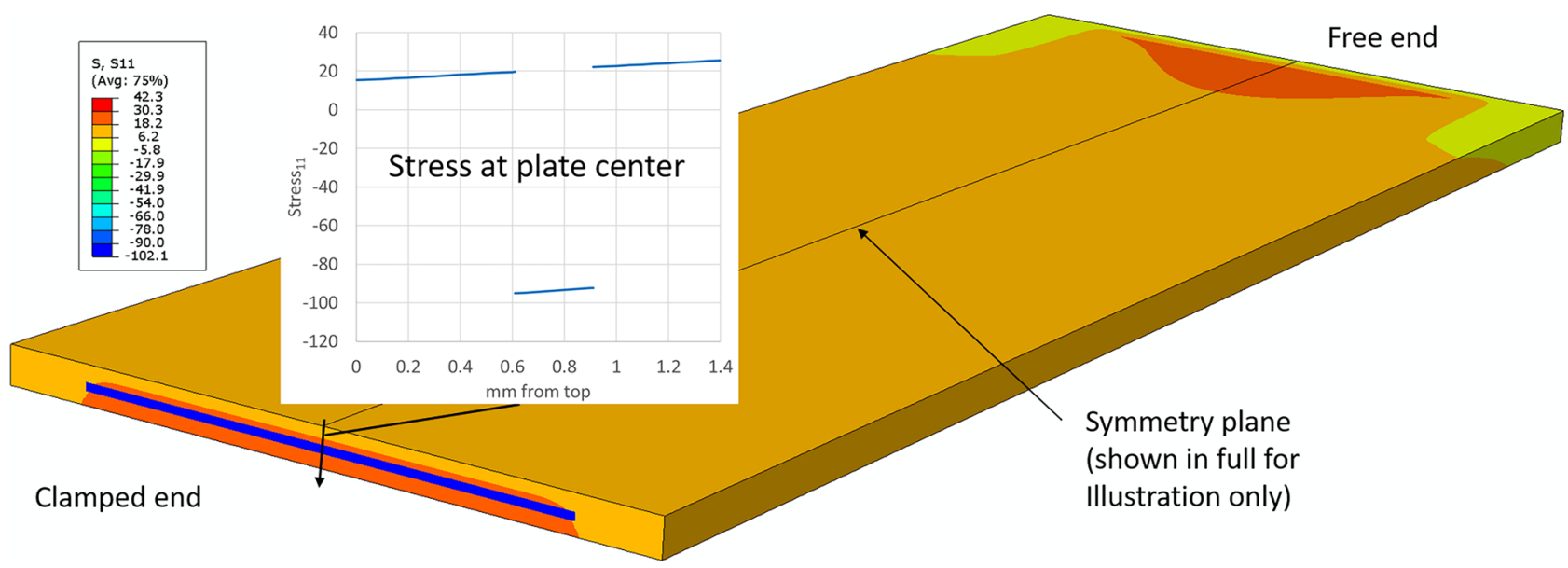

Fig. 9 A realistic stress state was used in the finite-element study to verify the 3D correction

which are detailed below. The 3D model can then simulate the incremental slitting and generate pseudo data. The pseudo data was analyzed using standard data analysis with all simplifying assumptions. The difference between the calculated stresses and known stresses then showed the error.

Figure 9 shows the 3D finite-element model of a miniplate initialized with a realistic, known residual stress. The stresses were initialized by cooling the initially stress-free assembly by $400{ }^{\circ} \mathrm{C}$ and allowing the differential thermal contraction to generate the stress elastically. The temperature magnitude was chosen to produce stress magnitudes similar to those measured in this study. However, it must be emphasized that this is in no way a predictive model for residual stresses in a mini-plate. The real process involves substantial plastic deformation in the aluminum cladding. Rather, this model is just a plausible residual stress state that has the desired 3D effects. As the cross section at the clamped edge of the plate in Fig. 9 shows, the central U-10Mo core is in a nearly uniform compressive-stress state. The aluminum is in tension over the entire cross section with some modest spatial variations. A comparison with neutron-diffraction measurements, see Fig. 12 in [11], indicates that the overall stress distribution is realistic for post-HIP stresses. The inset plot in Fig. 9 is a lineout of the residual stress at the center of the plate, which is the stress profile we desire to measure in the experiment. The profile shows the expected tension-compression-tension variation through the thickness. The small linear slope in the profile occurs because aluminum layers above and below the U-10Mo have different thicknesses, as is typical in mini-plates, and results in a bending stress component of the profile to satisfy moment equilibrium.

Starting from the initial residual stress state, incremental slitting was simulated by removing appropriate elements as shown in Fig. 3, which also indicates where the displacement pseudo data was extracted to mimic the experiment.

The pseudo data was analyzed using the standard 2D data analysis. To aid in interpretation, uncertainties were also calculated as if there were $1 \mu \mathrm{m}$ uncertainty in the displacements. Figure 10 compares the analysis results with the stresses from the 3D model as shown in Fig. 9. First, compare the results of the 2-D analysis to the known stresses at the mid-width of the plate. The stresses in both aluminum cladding layers match the known stresses to within uncertainty. Each of the two data points that effectively straddle a material interface return a stress that is some average of the nearby stresses in each material. The calculated compressive stresses in the U-10Mo fuel layer, however, are significantly lower in magnitude than the known stress. The reduced magnitude is plausible considering that a slit-depth increment in the U-10Mo also releases some tensile stress in aluminum laterally outside the U-10Mo.

We hypothesize that the stresses given by the $2 \mathrm{D}$ analysis represent a weighted average of the stresses across the entire width of the plate. For the purpose of correcting the $2 \mathrm{D}$ analysis and getting a more accurate measure of local stresses in the U-10Mo, this hypothesis was investigated quantitatively. Figure 11 shows the stresses from Fig. 9 with the scale zoomed in to show the details of the stresses in the aluminum. In the aluminum regions above and below the U-10Mo, the stresses are quite uniform in the lateral (y) direction. In the region outside of the U-10Mo (-y in the figure), the stresses are also mostly uniform laterally once they transition to a value lower than that in the central region. A careful analysis of the stresses in Fig. 11 shows that value, for the $\mathrm{z}$-values where there is aluminum across the whole specimen, to consistently be $60 \%$ of the corresponding value in the aluminum in the central region. The 
Fig. 10 Comparing the 2D analysis results to the known stresses from the 3D simulation shows that the "measured" stresses are closer to a weighted average of the stresses averaged across the width than to the stresses at the mid-width of the plate. Scaling up the 2Dcalculated stresses gives excellent agreement with the known stresses in the U-10Mo foil

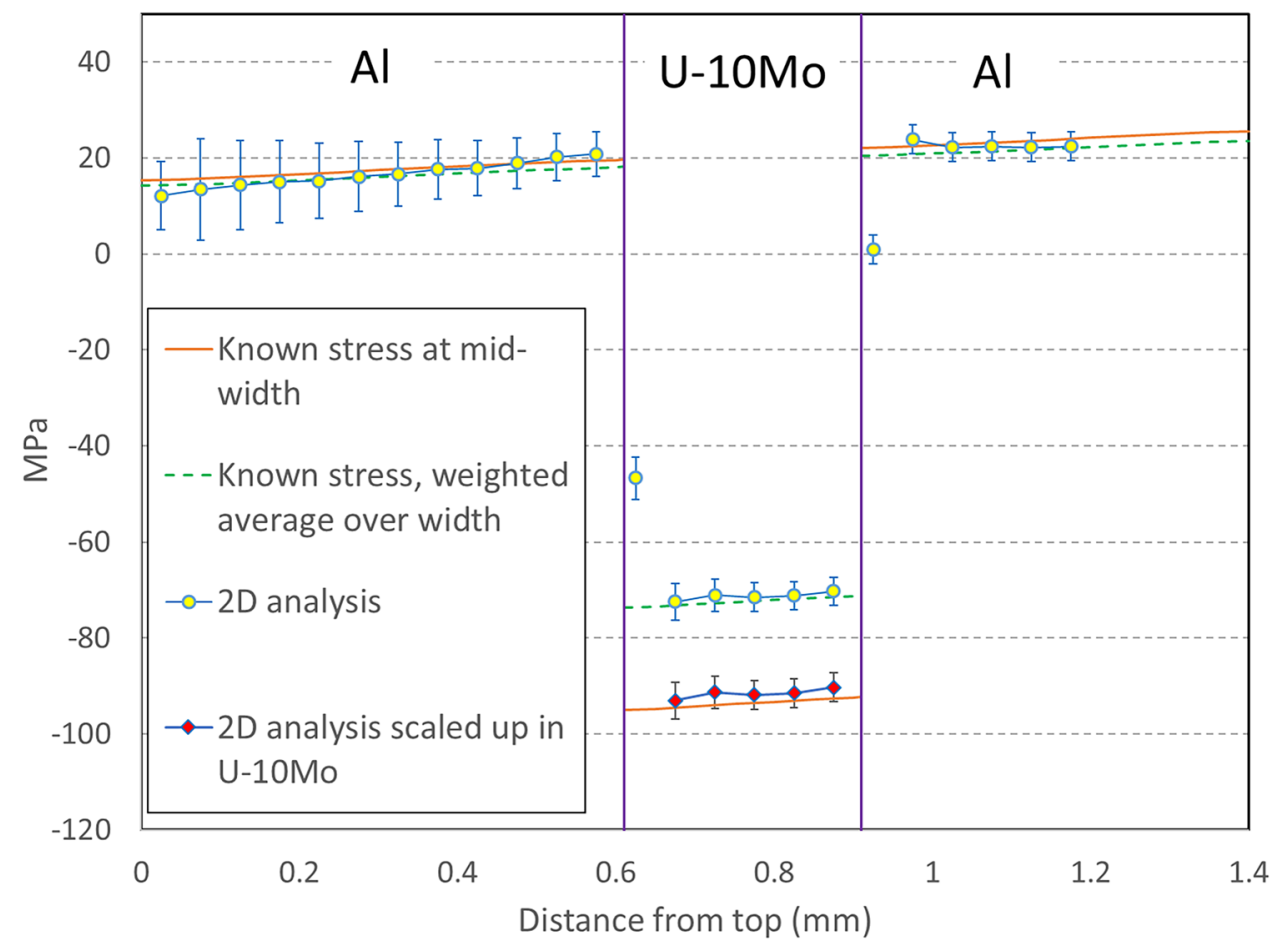

lower stress magnitude makes sense because the thermal mismatch with the U-10Mo drives the stresses, and the $\mathrm{U}-10 \mathrm{Mo}$ is not as close.

Considering the stresses are nearly uniform (y-direction) in the central and lateral regions, a simple weighted average was constructed and adjusted to match the $2 \mathrm{D}$ analysis results. Figure 10 shows that a weighted average taken from the FEM of central region have slightly more effect on the measured displacements. Carrying an additional significant figure in the constants in eq. (5) would slightly improve the agreement, but is not warranted by the empirical nature of this correction and would imply unrealistic accuracy. Equation (5) is a purely empirical result limited to the geometry of the miniplate specimens in this study.

We would like to correct the 2D analysis to better approx-

Weighted average stresses $=0.8($ Central stresses $)+0.2($ Lateral stresses $)$

matches the results of the $2 \mathrm{D}$ analysis very well. If the average were purely based on cross-section area, the ratio would be 3:1 instead of $4: 1$, which indicates that stresses in the imate the local stresses in the U-10Mo. The agreement of the $2 \mathrm{D}$ analysis with the weighted-average stresses suggests a correction, which is also shown in Fig. 10. Basically, eq. (5)
Fig. 11 The stresses in the aluminum are about $40 \%$ lower in the region laterally outside the U-10Mo (left side of figure) than in the central region at the same $z$ value. Shown on a halfsymmetry (y-direction) model and on a cross section at the $\mathrm{x}$-location of the slit

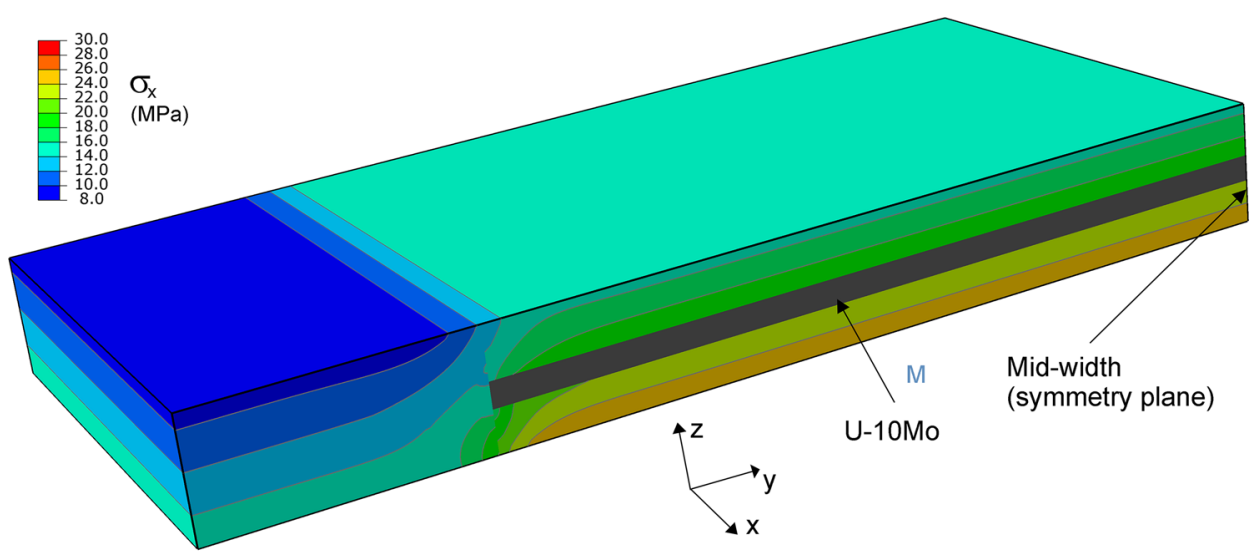




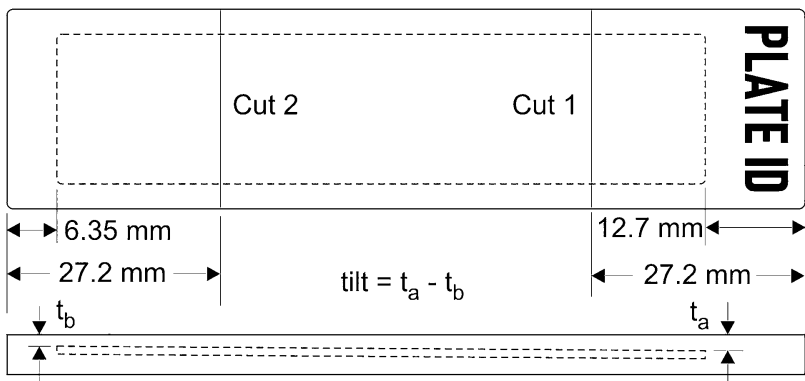

Fig. 12 With all specimens, two slits were made at either end of the plate to test for repeatability or for validation testing. The tilt in the fuel had an effect on the measurements. (In the bottom section, vertical dimensions are exaggerated by a factor of 4 )

is solved for the central stresses from the weighted average stresses given by the 2D analysis. Since Fig. 10 shows that the weighted average is not significantly different that actual stresses in the aluminum layers, the correction is only applied in the U-10Mo. In an actual measurement, the stresses in the aluminum lateral to the U-10Mo, used in eq. (5), are unknown. As a reasonable approximation, the average of the stresses measured in the all-aluminum layers is used and then multiplied by $60 \%$ per the results in Fig. 11 . That makes the correction
Table 1 Six specimens with LEU foils and one with a DU foil were tested in this study. The LEU specimens are sorted by foil thickness

\begin{tabular}{llllll}
\hline Specimen & $\begin{array}{l}\text { Al+Zr } \\
\text { thickness, } \\
\text { top, avg } \\
(\mu \mathrm{m})\end{array}$ & $\begin{array}{l}\text { Fuel foil } \\
\text { thickness } \\
(\mu \mathrm{m})\end{array}$ & $\begin{array}{l}\text { Al+Zr } \\
\text { thickness, } \\
\text { bot., avg } \\
(\mu \mathrm{m})\end{array}$ & $\begin{array}{l}\text { Blister } \\
\text { annealed }\end{array}$ & Tilt $(\mu \mathrm{m})$ \\
\hline $98-1$ & 624 & $250 \mathrm{DU}$ & 516 & No & 37 \\
$\mathrm{~A} 1 \mathrm{~B} 106$ & 565 & $245 \mathrm{LEU}$ & 457 & Yes & 44 \\
$\mathrm{~A} 1 \mathrm{C} 1103$ & 470 & $301 \mathrm{LEU}$ & 470 & No & -25 \\
$\mathrm{~A} 1 \mathrm{C} 177$ & 445 & $315 \mathrm{LEU}$ & 483 & No & 0 \\
$\mathrm{~A} 2 \mathrm{C} 178$ & 279 & $657 \mathrm{LEU}$ & 279 & No & 0 \\
A2C150 & 279 & $690 \mathrm{LEU}$ & 248 & No & 6 \\
A2B104 & 286 & $692 \mathrm{LEU}$ & 279 & Yes & 32 \\
\hline
\end{tabular}

of the thermal treatment as will be discussed later. To date, all testing on as-manufactured mini-plates have shown low stress magnitudes in the aluminum [11]. The correction also assumes that the stresses within the U-10Mo are uniform across the width. The symmetry inherent in the thermal environments, both during fabrication and during use in a reactor, suggest this assumption is reasonable. In any case, the correction adds additional uncertainty to the results and they should be interpreted accordingly.

Central stresses $=[(2 D$ analysis results $)-(0.6) *(0.2)($ Al avg.stress $)] / 0.8$,

which is applied to each value in the U-10Mo. With this correction to scale up the stresses, the agreement with the known stresses in the U-10Mo is then excellent as shown in Fig. 10. One could imagine using other approximations for the stresses in the aluminum lateral to the U-10Mo, such as the stresses measured nearest to the U-10Mo rather than the average or ignoring the $60 \%$ factor. When applied to the measurement results shown later in this work, such variations in the correction changed the final results by $5 \mathrm{MPa}$ or less, which is not significant compared to other uncertainties. To account for this uncertainty, an additional error source of $5 \mathrm{MPa}$ was added to the uncertainties for all corrected stresses in the U-10Mo. The previous calculated uncertainties in the U-10Mo stresses were also multiplied by the 1.25 (=1.0/0.8) factor from eq. (6).

Applying this scaling correction for the stresses in U-10Mo relies on the assumptions described above. The assumptions were illustrated on the particular case shown in Fig. 9, but are based on the basic mechanics of the thermal mismatch-driven stresses and the geometry of the fuel plate. The assumption about the aluminum stresses are uncertain but have minimal effect because of the 0.12 $(=0.6 \times 0.2)$ factor on them in eq. (6). Also, the stress magnitudes in aluminum are low, being limited because

\section{Experimental Validation and Application}

Experimental testing reported here includes two sets of tests. First, two measurements on a single fuel plate with DU were used to validate the novel aspects of the proposed measurements. One measurement represented the newly proposed method, and the cut was made with an end mill and displacements were measured. A second cut represented conventional practice and used wire EDM for making the slit and used a strain gauge in addition to the displacement measurement. Figure 12 shows that the two cuts were made at opposite ends of the plate and also defines tilt in the U-10Mo fuel.

The second set of tests applied the new method on six unirradiated fuel plates with LEU. Two cuts at opposite ends of each plate were again made in each specimen, this time to assess measurement repeatability. The six plates had different thicknesses for the U-10Mo foil to study the effect of foil thickness on the initial residual stress state. Fuel foil thicknesses were chosen to represent the fuel geometry and irradiation conditions (power density and surface heat flux) of the reactors being targeted for conversion. Table 1 lists the geometrical details of all the tested specimens. 
Fig. 13 Displacement and strain data from slitting tests with EDM and end mill slitting on specimen $98-1$ with a DU foil. The plot also shows the strains or displacements given by the inverse solutions discussed in the Results section

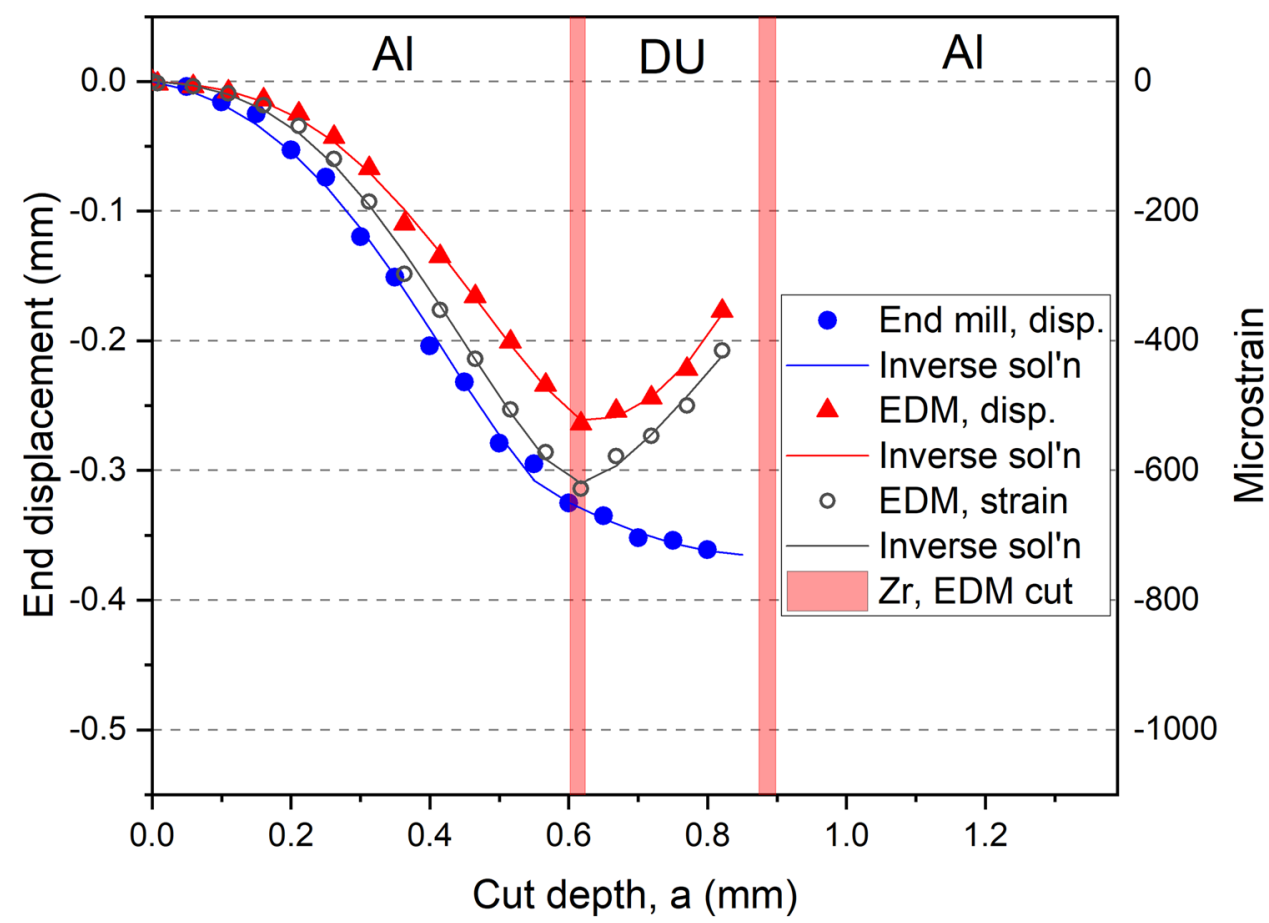

The testing of plates with LEU was performed in a mockup facility suitable for testing pre-irradiation LEU fuel and used the standard remote manipulators. Testing of the plates with DU was performed in laboratory facilities. All testing to date has qualified the system for upcoming use in a hot cell on irradiated fuel.

\section{Specimen Fabrication}

The mini-plates used for residual stress testing were fabricated based on the process developed during lab-scale fuel system development $[1,59]$. The fabrication process of the LEU U-Mo monolithic fuel system involves four steps: 1) casting of the U-10Mo alloy; 2) foil rolling; 3) bonding of the cladding by HIP, and 4) finishing and inspection. Casting involves vacuum induction melting of the constituent U-10Mo and molybdenum source materials to form an ingot with the nominal $19.75 \%{ }^{235} \mathrm{U}$ enrichment. The ingots are then finished into coupons. During foil fabrication, the coupons are stacked with $\mathrm{Zr}$ foils on top and bottom surfaces of each foil and sealed in a carbon steel can where they are then hot co-rolled to produce the fuel core (U-10Mo with bonded $\mathrm{Zr}$ interlayer). The $\mathrm{Zr}$ diffusion barrier is nominally $25 \mu \mathrm{m}$ thick after rolling. The fuel core is removed from the can and cold rolled to final thickness and sized to final dimension prior to being clad in AA 6061 during HIP bonding. To fix the position of the fuel core, a pocket is machined into one of two AA 6061 sheets that comprise the fuel cladding. The sheets are then chemically cleaned, and the fuel foil is placed in the pocket with the second AA 6061 sheet placed on top to form the alternating layers of the fuel plate stack ups. Several of these stack ups are assembled with stainless steel "strong backs" separating them, and the entire assembly is placed into a HIP can and hermetically sealed. The HIP can is then processed at elevated pressure and temperature (nominally $560{ }^{\circ} \mathrm{C}$ and $103 \mathrm{MPa}$ for $90 \mathrm{~min}$ ) to bond the AA $6061 \mathrm{clad}-$ ding to itself and to the fuel core, thus forming the fuel plate. After processing, the HIP undergoes a controlled cooling rate. Following removal from the HIP can, individual plates are sized to final dimension by combination of shearing and machining to produce the final fuel plate. In the case of miniplates used for residual stress measurements, the nominal dimensions are $25.4 \mathrm{~mm} \times 101.6 \mathrm{~mm} \times 1.27 \mathrm{~mm}$. For quality control, plates can receive a blister anneal treatment and inspection to confirm adequate clad bonding [60]. Two of the plates in this study received a blister anneal, see Table 1 . The blister anneal involves heating to $485{ }^{\circ} \mathrm{C} \pm 20{ }^{\circ} \mathrm{C}$ for $30 \mathrm{~min}$, followed promptly by air cooling. The annealing temperature of AA 6061 is $410{ }^{\circ} \mathrm{C}$ and that of U-10 Mo is $650{ }^{\circ} \mathrm{C}$. Additional information about the characterization of these fuel plates is available [61-63].

\section{Testing and Data}

Figure 13 shows the data from specimen $98-1$ with a DU foil, which was cut once with the end mill and once with wire EDM. The strain scale is adjusted for qualitatively comparing strain data to displacements. The approximate location on the $\mathrm{Zr}$ interlayers are shown at the location of the EDM cut. They were not measured near the end mill 
cut. For the EDM test, the strain data trends compare well with the displacement data. Quantitative comparisons can only be discussed once stresses are calculated. For comparing the EDM to the end mill tests, the displacements follow approximately the same trends while cutting through the Al. After the slit enters the foil, the displacement trends diverge, which will be interpreted after we calculate stresses. In the $\mathrm{Al}$, displacements from the end mill cut are about 50\% greater than for the EDM cut. This difference occurs because the end mill slit, at $0.79 \mathrm{~mm}$, is about 2.5 times as wide as the EDM slit, which was about $0.31 \mathrm{~mm}$. Figure 3 shows that the cantilever deforms like a hinge with the largest deformations occurring under the slit. A wider slit allows more rotation under the slit and gives larger displacements at the end. The FEM coefficients used in the data analysis include this geometry difference and should account for this effect.

In all cases, the results from the two displacement sensors on opposite faces of the plate gave virtually identical results, so the average is used. Such agreement illustrates the repeatability of the eddy-current sensor and indicates that the dual sensor setup gives redundancy in case one sensor fails.

Figure 14 shows the data from three of the six LEU plates tested, which were chosen to represent the range of results. The plot indicates the approximate location of the $\mathrm{Zr}$ layers. In the cases with tilt in the fuel foil, the location is not at the same depth for the two cuts. The extent of the x-axis in each plot corresponds to the full thickness of the specimen. It can be observed that the thicknesses of the two aluminum layers can be quite different.

Comparing the data between the two cuts on a given plate suggests that the testing is more repeatable than the specimens are uniform. Figure 14(a) shows repeatable data between the two cuts on a thin foil specimen that had no measurable tilt in the fuel. Figure 14(b) shows a noticeable difference between the two cuts. That plate had a tilt of about $44 \mu \mathrm{m}$ along the length of the specimen, about $18 \%$ of the fuel thickness. Figure 14(b) also shows that the specimen with the thinnest foil had larger magnitude displacements. Figure 14(c) shows the data from cuts on a thick foil specimen that had no measurable tilt. The data is repeatable between the two cuts, with some divergence as the cut penetrates past halfway through the fuel. Data on the other specimens not plotted here show a similar correlation between a tilt in the foil and differences between data on the two cuts. The correlation is not perfect, however, presumably because other non-uniformities in the specimen are not captured by the tilt measurement.

\section{Results}

One measure of the quality of an inverse solution is its ability to reproduce the data. Figures 13 and 14 also include the displacements or strains given by the inverse solution.
The inverse solutions modestly smooth through the noisy data but fit the features in the data quite well. The level of regularization qualitatively seems appropriate.

\section{Validation Testing on Plate with DU Foil}

Figure 15 shows the stresses from the validation test, calculated from the data in Fig. 13. For all stress plots in the results, each stress point is plotted at the midpoint of a cut depth increment. If the cut depth increment overlaps more than one material, the data point represents an unknown average in stresses in those materials, and is therefore not connected by a line to the rest of the stress profile.

Generally, the agreement between the three results in Fig. 15 is good. First, we will compare the strain and displacement results for the EDM cut. The stresses in the aluminum test agree nearly perfectly between the displacement and strain data, which gives good confidence for the use of displacement instead of strain. In the DU foil, the displacementbased stresses are more compressive by approximately $25 \%$ on average. Further analysis of the FEM study of the 3D correction showed that the strain gauge does not average the stresses across the specimen width as well as displacements because the strain gauge measures deformations more locally and over only a small portion of the width. Therefore, the $3 \mathrm{D}$ correction is more accurate for the displacement data. Overall, replacing strain data with displacements appears reasonable.

Now we compare the EDM cut results with those from the end mill cut. In the aluminum, the stresses agree well in sign and general distribution. There are some differences at the level of the uncertainties, some of which can likely be attributed to the $37 \mu \mathrm{m}$ tilt in the foil. Deeper into the foil, the end mill results are compressive like the EDM results and have a similar gradient. The end mill stresses in the DU foil are $12 \%$ and $30 \%$ less compressive than the strainbased and displacement-based stresses from the EDM cut, respectively. It will become apparent when we discuss the results from specimens with LEU that this discrepancy is likely caused by heterogeneity in the specimen more than errors in the measurements.

\section{Plates with LEU Foils}

The stress results for the specimens containing LEU are plotted in Fig. 16 and show good repeatability. For each plate, the stresses from the two cuts agree within uncertainty over much of the depth. The stress magnitudes in the LEU foil decrease significantly as the foil thickness increases, varying by as much as a factor of 10 . The stress magnitudes in the thick foil specimen are smaller, yet the displacements were still more than sufficient magnitude for a well-resolved measurement. 
Fig. 14 (a) Specimen A1C177 with a well-aligned thin foil gave very repeatable data on the two cuts. (b) Specimen A1C1103 with a tilted foil gave small differences in the data. (c) Specimen A2C178 with a wellaligned thick foil gave fairly repeatable data. The plots also show the displacements given by the inverse solution discussed in the "Results" section
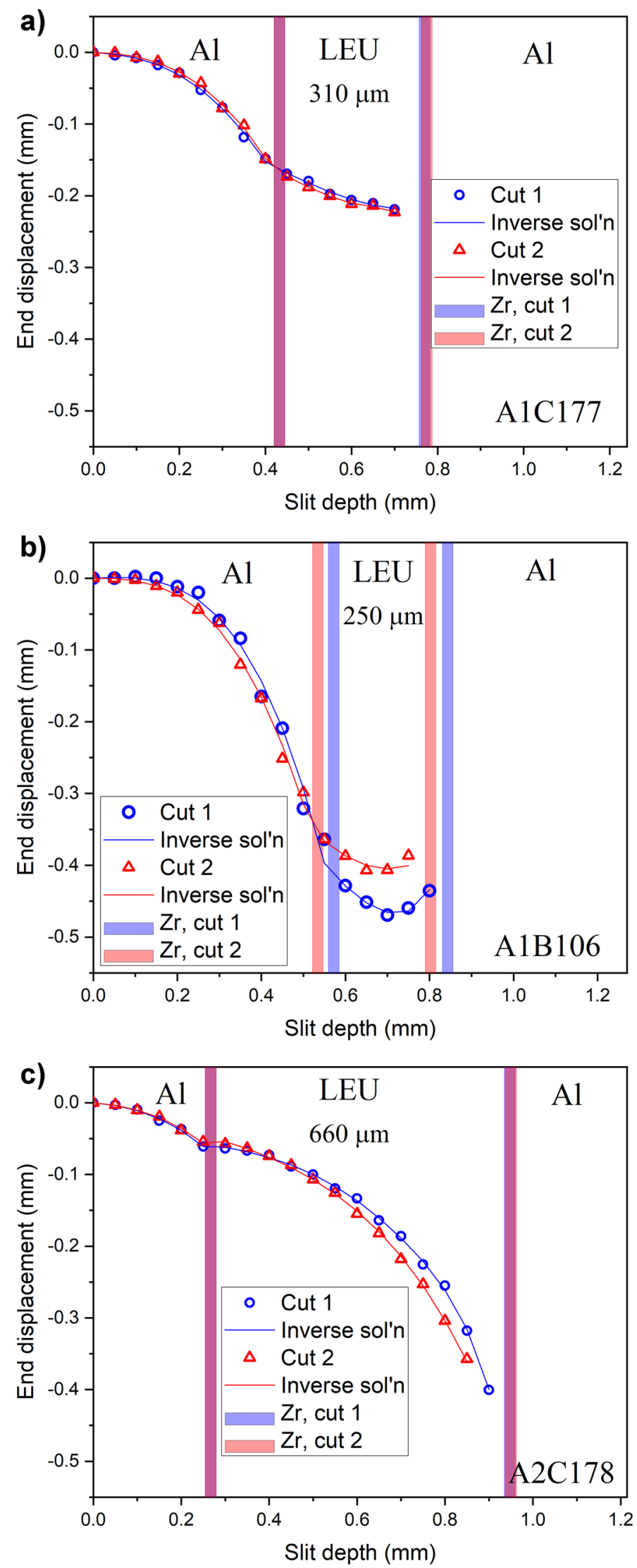
Fig. 15 A comparison between conventional slitting, with EDM and strain gauges, and the hotcell system gave fair agreement. The locations of the $\mathrm{Zr}$ layers were only measured on the side of the EDM cut

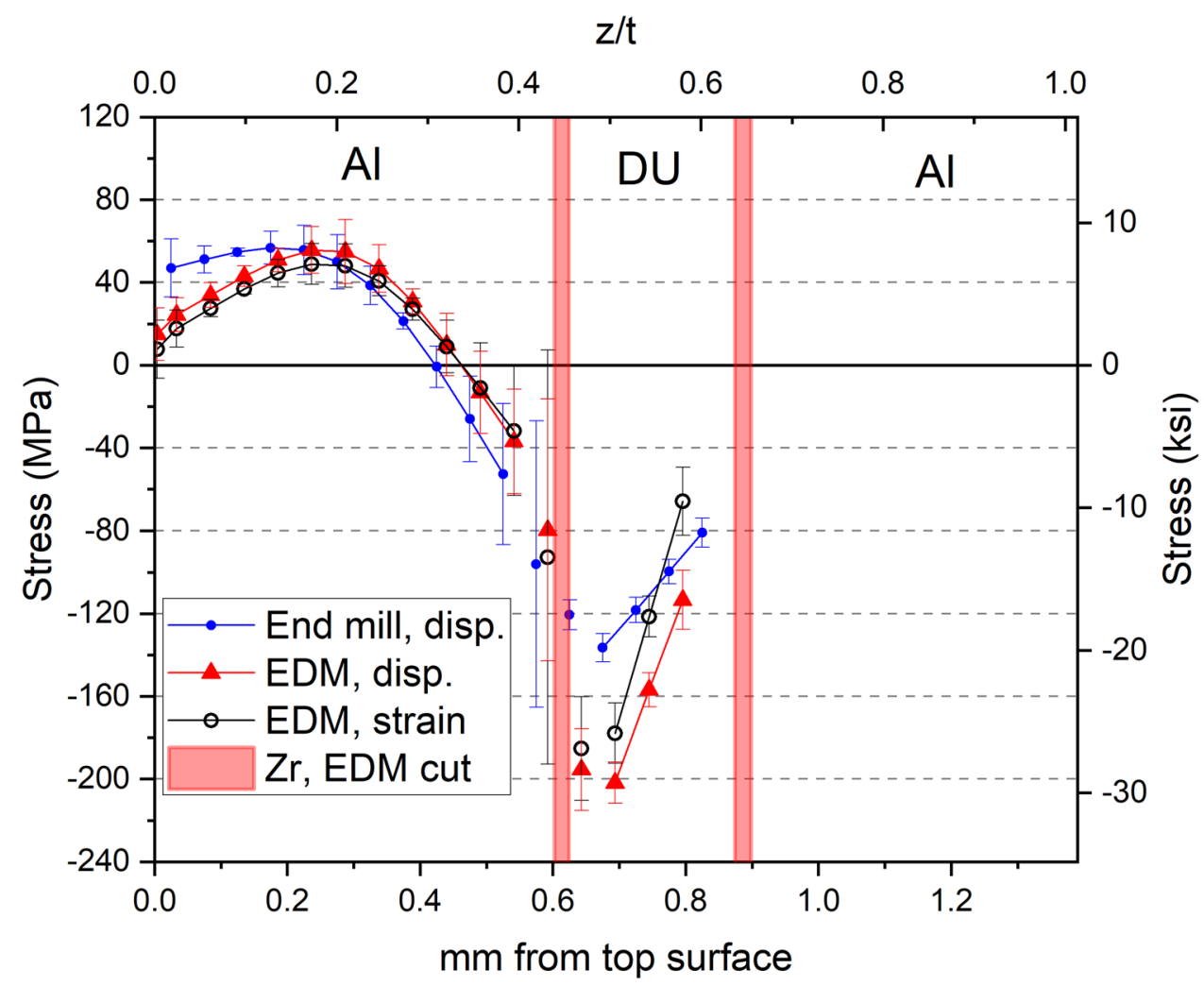

The largest difference between the two cuts is shown in Fig. 16(b). The stresses in the LEU foil for cut 1 appear about $20 \%$ more compressive than for cut 2 when they are compared at the same location. However, the locations of the $\mathrm{Zr}$ layers are shifted by about $390 \mu \mathrm{m}$ because of the tilt. Comparing the stresses at the same location relative to the $\mathrm{Zr}$ is likely more appropriate. Figure 17 shows that shifting the cut 2 stresses in the LEU foil by that $390 \mu \mathrm{m}$ makes the stresses agree with the cut 1 stresses, within uncertainty. In that same specimen, the stresses in the LEU foil vary more strongly with position than in the other plates in Fig. 16. The $\mathrm{Zr}$ layer locations in Fig. 16(b) show that the Al layer thicknesses are much more asymmetric, which helps explain the asymmetric stress profile (i.e., the large gradient in the LEU foil stresses).

\section{Discussion}

The results on the as-fabricated (pre-irradiation) plates follow some trends dictated by the processing and material properties. The stresses generated by cooling down from treatment temperatures are generally tensile in the aluminum and compressive in the U-10Mo. The peak temperatures during the HIP and blister anneal are sufficient to reduce any pre-existing stresses on both materials to insignificant levels by yielding and creep [4]. As a plate cools, the greater thermal expansion coefficient for the aluminum causes it to contract more than the U-10Mo and pull the U-10Mo into compression with balancing tension in the aluminum.

The magnitudes of the residual stresses are primarily controlled by the constraint provided by the aluminum layers. As-received 6061 aluminum in the T651 temper has a yield strength of about $300 \mathrm{MPa}$. After going through the HIP cycle, the measured yield strength of the aluminum is about 50-75 MPa [64, 65], more similar to the 6061-O annealed temper. The 50-75 MPa yield strength is similar to the peak aluminum stresses observed in this study and neutron-diffraction measurements of similar plates [11]. Residual stresses at yield magnitude indicate that the aluminum stress is saturating and is limiting the residual stress in the U-10Mo foil. Because residual stresses must be in force balance, the ability of the aluminum to constrain the $\mathrm{U}-10 \mathrm{Mo}$ foil is limited by both the aluminum yield strength and its thickness. For a given yield strength, a larger aluminum thickness relative to U-10Mo thickness will allow the aluminum to support higher magnitude stresses in the $\mathrm{U}-10 \mathrm{Mo}$. To test this hypothesis, the stresses measured in this study at approximately the mid-thickness of the U-10Mo are plotted in Fig. 18 against the total aluminum thickness in the plate divided by the U-10Mo thickness, a simple measure of constraint. Increasing the constraint from about 0.8 to just over 4 increase the stresses in the U-10Mo by a factor of at least five. 

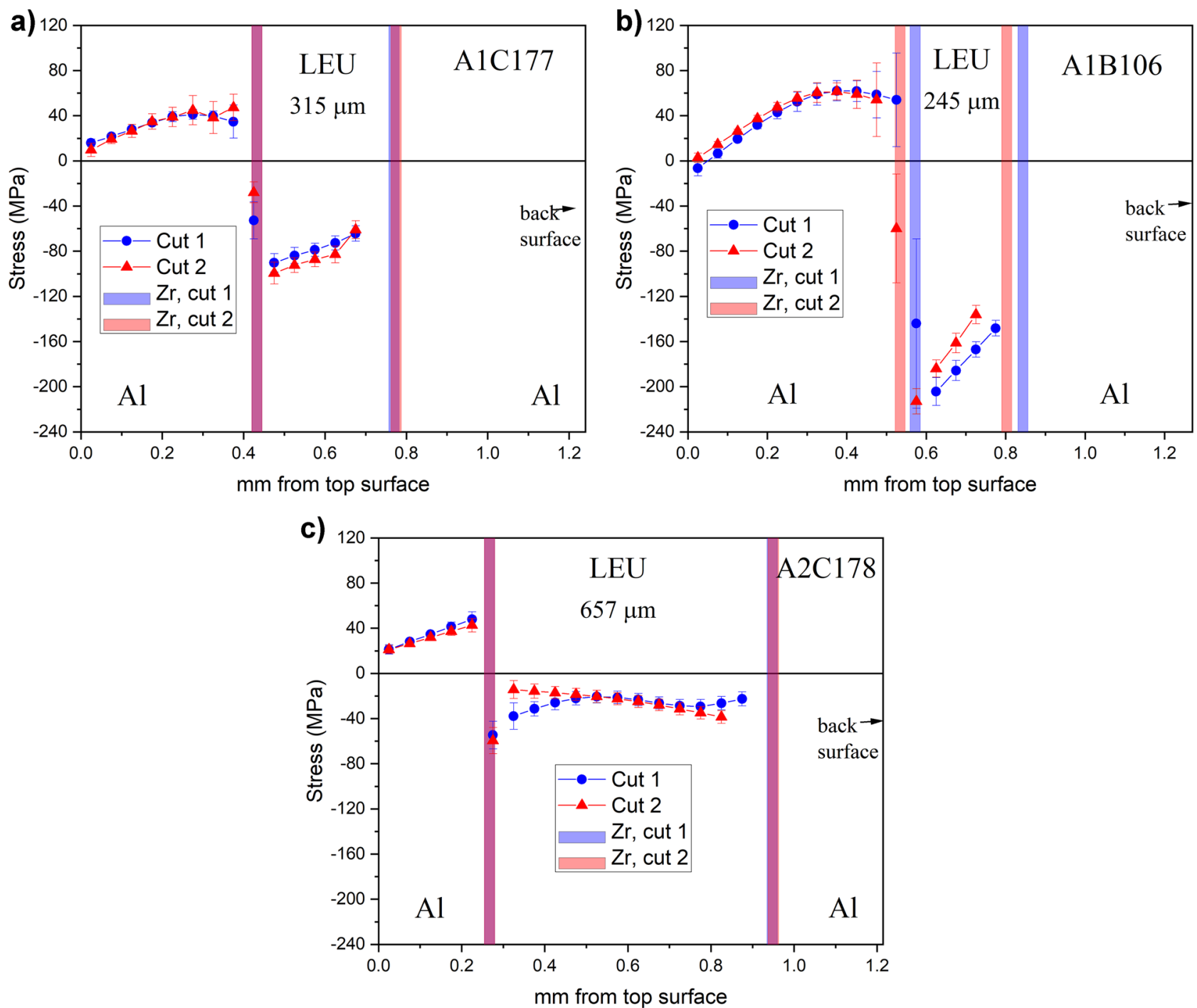

Fig. 16 Stress results from corresponding strains in Fig. 14. The thin plates, (a) and (b), give very repeatable stresses with compressive-stress magnitudes in the U-10Mo peaking close to $100 \mathrm{MPa}$. (c) Stresses in the thick foil specimen are much lower magnitude

A second factor is also affecting the residual stress magnitudes. A linear fit to the stress vs. constraint data is justified by the force balance argument and is shown in Fig. 18 for the data from this study. Plates that had the blister anneal follow a trendline with about a $67 \%$ steeper slope than the results from plates that only had the HIP treatment. One difference in the processes is the $560{ }^{\circ} \mathrm{C}$ HIP temperature compared to $485^{\circ} \mathrm{C}$ for the blister anneal. From a purely thermal mismatch perspective, the lower blister-anneal temperature would not explain those plates having increased stresses. However, the blister anneal temperature is below the solvus for AA 6061, unlike the HIP temperature, and might allow some age hardening, which could increase the strength and therefore the residual stresses. The blister anneal is well above typical maximum age hardening temperature of $260{ }^{\circ} \mathrm{C}$ [66], and this hypothesis does not seem to have any literature data to support it. A future measurement of yield strength of the AA 6061 after a blister anneal treatment could test the hypothesis. A more plausible explanation for the higher stress magnitudes after blister annealing appears to be the higher cooling rate. The slower cooling rates after HIP could be allowing the stresses to relieve further by viscoplasticity (i.e., creep) during cooling, so the final magnitudes are lower. Neutron diffraction studies of plates cooled at different rates from HIP, but without a subsequent blister anneal to confound the issue, showed that slower cooling reduced the residual stresses, supporting this argument [11].

Figure 18 also shows measurements taken from the literature on related plates, all with DU U-10Mo foils with $\mathrm{Zr}$ diffusion barriers HIP-clad with aluminum. When possible, the stresses were taken from the publications at locations similar to the slitting measurements. The correlation 


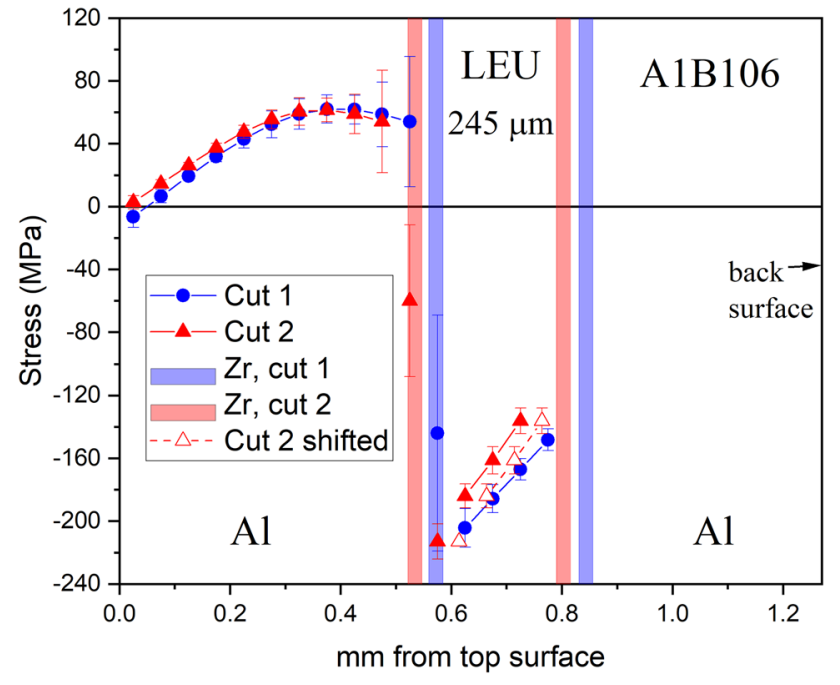

Fig. 17 If the stresses in the LEU foil for cut 2 are shifted the amount it would take to line up the zirconium layers for both cuts, the agreement with cut 1 is much better

between the stress level and constraint persists throughout the various measurements. Extrapolations of the linear fits to the data from LEU foils almost bound all of the literature data. Therefore, at least to some extent, the literature independently validates the results in this study. There are no apparent differences in stresses between LEU and DU foils, as expected since isotopic differences have minimal effect on mechanical properties. Taken as a whole, the results support the contention that the stresses are primarily caused by thermal mismatch stresses upon cooling from the HIP or from

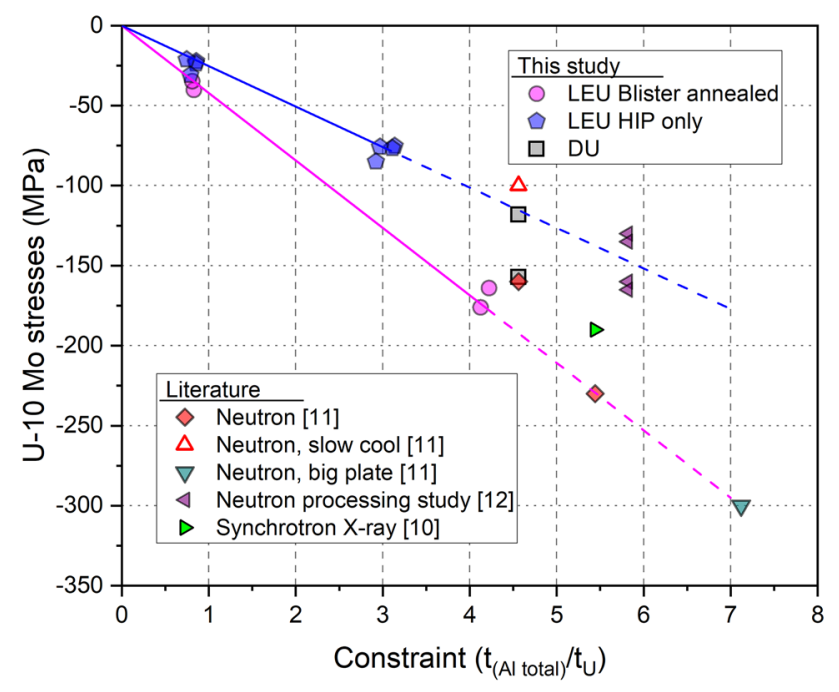

Fig. 18 In both this study and results from the literature, the residual stresses in the U-10Mo fuel correlate very well with the level of constraint provided by the aluminum cladding. The stresses also depend on the cooling rate, with the faster-cooled blister anneal treatment giving relatively high stress magnitudes the blister anneal rather than from earlier processing steps. Modeling [4] and measurements [12] both show that stresses prior to the HIP are relieved and have minimal effect on the final stresses. The neutron diffraction results plotted as diamonds in Fig. 18 [11] are from the same plate measured before (constraint $=5.4$ ) and after (constraint $=4.6$ ) thinning the aluminum cladding by machining. The decrease in stress magnitude after thinning follows the trend well and further supports the simple constraint argument. This study is the first to measure fuel plates with relatively thick U-10Mo layers and reveal the very low stresses when there is little aluminum to constrain the U-10Mo during cooling.

The literature results are also consistent with the cooling rate trends from our study. The neutron-diffraction measurement on a plate that was cooled at roughly $1 / 10^{\text {th }}$ of the normal rate [11] is slightly outside the bounds from this study. The plates in [12] saw a cooling rate $30 \%$ lower than the faster-cooled plates in [11] and also have lower magnitude residual stresses.

The $\mathrm{x}$-axis variable in Fig. 18 ignores any constraint from the aluminum laterally outside of the U-10Mo. A similar plot based on total cross section areas for the constraint gives somewhat poorer correlation, indicating the aluminum above and below the U-10Mo is providing the primary constraint.

As with all mechanical relaxation methods that assume elasticity when analyzing the data, the possibility of plasticity near the cut tip must be considered [67-69]. Although the stresses rise to about $200 \mathrm{MPa}$ in the U-10Mo in Fig. 17, the yield strength of U-10Mo is about $800 \mathrm{MPa}$ [61], so plasticity in the U-10Mo is not a concern. The reduced yield strength of the AA 6061 does, however, give cause for concern. A quantitative estimate of possible errors from plasticity in slitting measurements is available [70]. That methodology requires strain gauge data, not displacements, so we apply it to data from Fig. 13, with that test reasonably representative of the study as a whole. The samples in [65] that best represent the samples here give a strength of $70 \mathrm{MPa}$, which is used in the analysis. The maximum values of the normalized stress intensity factor is 0.6. Our tests satisfy the plain strain conditions, and that factor of 0.6 indicates an average error in the calculated residual stresses of up to $8 \%$ [70], which is acceptable. Furthermore, that analysis is conservative, notably in the assumption of no strain hardening. The AA 6061 after the HIP cycle shows significant strain hardening, [64], which would significantly reduce the errors $[70,71]$.

\section{Conclusions}

To measure residual stresses in nuclear reactor fuel plates with a U-10Mo fuel foil clad in AA 6061 by hot isostatic pressing, the incremental slitting method was successfully 
modified to work in the remote manipulation setting of a radiological hot cell. Two major changes were made to standard practice. First, replacing strain gauges with displacement sensors gave comparable residual stress results and accuracy. The cantilever displacements, unlike strains, scale with the length of the cantilever, which makes the applicability dependent upon specimen size. For smaller specimens, the loss of sensitivity would reduce the sensitivity of using displacements. Second, replacing wire EDM with a small end mill was acceptable but resulted in noisier data and some cutting difficulties. Future work to improve the cutting process could improve the hot cell system. Nonetheless, a comparison of modified measurements with traditional measurements on DU U-10Mo plate validated the modified method.

The stresses were measured for the first time in LEU U-10Mo fuel plates after the HIP bonding and the blister anneal thermal treatment but prior to irradiation. Variations between repeat measurements were strongly correlated with measured geometrical heterogeneity in the plate - a tilt in the fuel U-10Mo foil. Overall, differential thermal contraction during cooling from the HIP temperature caused compressive stresses in the foil balanced by tension in the aluminum cladding. The tensile stresses in the aluminum were limited by the low aluminum strength after slow cooling from the HIP. The foil stresses were in turn limited by the stresses and the amount of constraint provided by the aluminum. A simple measure of constraint, the total aluminum thickness divided by the U-10Mo thickness, was strongly correlated with the compressive-stress magnitude in the U-10Mo. Measurements in the literature on DU U-10Mo plates relative to the same constraint measure fit the same trend well, but the results here extended the trend further into low constraint and therefore low-stress regions. Because the measured stresses in the U-10Mo were higher when a plate was cooled more quickly from high temperature, our results also indicated creep in the aluminum plays a role. The ability to measure the stresses in unirradiated plates validates the new method but is not the important application. It is the shutdown-induced post-irradiation stresses that are the true concern for evaluating potential failure modes and assessing fuel failure limits. Because other methods are impractical in a hot cell, the modified slitting method is now poised to measure those stresses for the first time.

Acknowledgements This work was supported by the Department of Energy National Nuclear Security Administration, Office of Nuclear Materials Threat Reduction (NA-212) under DOE-NE Idaho Operations Office contract DE-AC07-05ID14517. Los Alamos National Laboratory is operated by Triad National Security, LLC for the National Nuclear Security Administration of U.S. Department of Energy (Contract No. 89233218CNA000001).

\section{Declarations}

Conflicts of Interest The authors declare that they have no conflict of interest.

Open Access This article is licensed under a Creative Commons Attribution 4.0 International License, which permits use, sharing, adaptation, distribution and reproduction in any medium or format, as long as you give appropriate credit to the original author(s) and the source, provide a link to the Creative Commons licence, and indicate if changes were made. The images or other third party material in this article are included in the article's Creative Commons licence, unless indicated otherwise in a credit line to the material. If material is not included in the article's Creative Commons licence and your intended use is not permitted by statutory regulation or exceeds the permitted use, you will need to obtain permission directly from the copyright holder. To view a copy of this licence, visit http://creativecommons.org/licenses/by/4.0/.

\section{References}

1. Jue J-F, Park BH, Clark CR, Moore GA, Keiser DD (2010) Fabrication of Monolithic RERTR Fuels by Hot Isostatic Pressing. Nucl Technol 172(2):204-210. https://doi.org/10.13182/ NT10-A10905

2. Ozaltun H, Herman Shen MH, Medvedev P (2011) Assessment of residual stresses on U10Mo alloy based monolithic mini-plates during Hot Isostatic Pressing. J Nucl Mater 419(1):76-84. https:// doi.org/10.1016/j.jnucmat.2011.08.029

3. Medvedev PG, Ozaltun H, Robinson AB, Rabin BH (2018) Shutdowninduced tensile stress in monolithic miniplates as a possible cause of plate pillowing at very high burnup. Nucl Eng Des 328:161-165. https://doi.org/10.1016/j.nucengdes.2018.01.004

4. Ozaltun H (2015) The Effects of Fabrication Induced Residual Stress-Strain States on the Irradiation Performance of Monolithic Mini-Plates. In: ASME 2015 International Mechanical Engineering Congress and Exposition, Houston, Texas, p V06BT07A029. https://doi.org/10.1115/imece2015-53050

5. Rice F, Williams W, Robinson A, Harp J, Meyer M, Rabin B (2015) RERTR-12 Post-irradiation examination summary report. Idaho National Lab, Idaho Falls, ID (United States). https://doi. org/10.2172/1173078

6. Kim YS, Hofman GL, Cheon JS, Robinson AB, Wachs DM (2013) Fission induced swelling and creep of U-Mo alloy fuel. J Nucl Mater 437(1):37-46. https://doi.org/10.1016/j.jnucmat.2013.01. 346

7. Kim YS, Hofman GL (2011) Fission product induced swelling of U-Mo alloy fuel. J Nucl Mater 419(1):291-301. https://doi.org/ 10.1016/j.jnucmat.2011.08.018

8. Withers PJ, Bhadeshia HKDH (2001) Residual stress-Part 1Measurement techniques. Mater Sci Technol 17(4):355-365. https://doi.org/10.1179/026708301101509980

9. Schajer GS (2013) Practical residual stress measurement methods. John Wiley \& Sons, Chichester, West Sussex, UK

10. Brown DW, Okuniewski MA, Almer JD, Balogh L, Clausen B, Okasinski JS, Rabin BH (2013) High energy X-ray diffraction measurement of residual stresses in a monolithic aluminum clad uranium-10wt\% molybdenum fuel plate assembly. J Nucl Mater 441(1-3):252-261. https://doi.org/10.1016/j.jnucmat.2013.05.064

11. Brown DW, Okuniewski MA, Clausen B, Moore GA, Sisneros TA (2016) Neutron diffraction measurement of residual stresses in Al-clad U-10Mo fuel plates. J Nucl Mater 474:8-18. https:// doi.org/10.1016/j.jnucmat.2016.02.012 
12. Brown DW, Okuniewski MA, Sisneros TA, Clausen B, Moore GA, Balogh L (2016) Neutron diffraction measurement of residual stresses, dislocation density and texture in $\mathrm{Zr}$-bonded $\mathrm{U}-10 \mathrm{Mo}$ “mini” fuel foils and plates. J Nucl Mater 482:63-74. https://doi. org/10.1016/j.jnucmat.2016.09.022

13. Lu J, James M, Roy G (1996) Handbook of Measurement of Residual Stresses. Fairmont Press, Lilburn, GA

14. Holden TM (2013) Neutron Diffraction. In: Schajer GS (ed) Practical Residual Stress Measurement Methods. John Wiley \& Sons, Ltd, pp 195-223. https://doi.org/10.1002/9781118402832.ch8

15. Prevey PS (1986) X-ray diffraction residual stress techniques. In: Mills K (ed) Metals Handbook, vol 10. ASM International. Metals Park, OH, pp 380-392

16. Wahlquist DR (1998) Equipment design guidelines for remote hot cell operations. Argonne National Lab., IL (US) Report ANL/ED/ CP-95878. https://www.osti.gov/servlets/purl/10686

17. Hill MR (2013) The Slitting Method. In: Schajer GS (ed) Practical Residual Stress Measurement Methods. John Wiley \& Sons, Ltd, pp 89-108. https://doi.org/10.1002/9781118402832.ch4

18. Cheng W, Finnie I (2007) Residual Stress Measurement and the Slitting Method. Springer Science+Business Media, LLC, New York, NY, USA (Mechanical Engineering Series)

19. Schajer GS, Whitehead PS (2018) Hole-Drilling Method for Measuring Residual Stresses. Synth SEM Lect Exp Mech 1(1):1186. https://doi.org/10.2200/S00818ED1V01Y201712SEM001

20. Cheng W, Finnie I, Gremaud M, Prime MB (1994) Measurement of near-surface residual-stresses using electric-discharge wire machining. J Eng Mater Technol 116(1):1-7. https://doi.org/10. 1115/1.2904251

21. Prime MB, Lovato ML, Alexander DJ, Beard TV, Clarke KD, Folks BS (2014) Incremental Slitting Residual Stress Measurements for a Hot Cell. Los Alamos National Laboratory, New Mexico. https://doi.org/10.2172/1131008.ReportLA-UR-14-23273

22. Steinzig M, Broetto FZ (2014) Residual Stress measurements in thin composite plates using the hole drilling technique. Los Alamos National Laboratory, New Mexico. https://doi.org/10.2172/ 1159052.ReportLA-UR-14-23956

23. Steinzig M, Ponslet E (2003) Residual Stress Measurement Using The Hole Drilling Method And Laser Speckle Interferometry: Part I. Exp Tech 27(3):43-46. https://doi.org/10.1111/j.1747-1567. 2003.tb00114.x

24. Schajer GS, Steinzig M (2005) Full-field calculation of hole drilling residual stresses from electronic speckle pattern interferometry data. Exp Mech 45(6):526-532. https://doi.org/10.1007/ BF02427906

25. Wong W, Hill MR (2013) Superposition and Destructive Residual Stress Measurements. Exp Mech 53(3):339-344. https://doi.org/ 10.1007/s11340-012-9636-y

26. Strantza M, Vrancken B, Prime MB, Truman C, Rombouts M, Brown DW, Guillaume P, Van Hemelrijck D (2019) Directional and oscillating residual stress on the mesoscale in additively manufactured Ti-6Al-4V. Acta Mater 168:299-308. https://doi.org/10. 1016/j.actamat.2019.01.050

27. Prime MB, Hill MR (2004) Measurement of Fiber-Scale Residual Stress Variation in a Metal-Matrix Composite. J Compos Mater 38(23):2079-2095. https://doi.org/10.1177/0021998304045584

28. Beghini M, Loffredo M, Monelli BD, Bagattini A (2018) Residual stress measurements in an autofrettaged cylinder through the Initial Strain Distribution method. Int J Press Vessel Pip 168:87-93. https://doi.org/10.1016/j.ijpvp.2018.09.007

29. Kapadia P, Davies C, Pirling T, Hofmann M, Wimpory R, Hosseinzadeh F, Dean D, Nikbin K (2017) Quantification of residual stresses in electron beam welded fracture mechanics specimens. Int J Solids Struct 106:106-118. https://doi.org/10. 1016/j.ijsolstr.2016.11.028
30. Hosseinzadeh F, Toparli MB, Bouchard PJ (2012) Slitting and Contour Method Residual Stress Measurements in an Edge Welded Beam. J Press Vessel Technol 134(1):011402-011406. https://doi.org/10.1115/1.4004626

31. Ronevich JA, D'Elia CR, Hill MR (2018) Fatigue crack growth rates of X100 steel welds in high pressure hydrogen gas considering residual stress effects. Eng Fract Mech 194:42-51. https://doi. org/10.1016/j.engfracmech.2018.02.030

32. Lee MJ, Hill MR (2007) Intralaboratory repeatability of residual stress determined by the slitting method. Exp Mech 47(6):745752. https://doi.org/10.1007/s11340-007-9085-1

33. Prime MB (2003) Experimental procedure for crack compliance (slitting) measurements of residual stress. Los Alamos National Laboratory, New Mexico. https://doi.org/10.13140/RG.2.2.21741. 54246 (Report LA-UR-03-8629)

34. Prime MB (1999) Residual stress measurement by successive extension of a slot: The crack compliance method. Appl Mech Rev 52(2):75-96. https://doi.org/10.1115/1.3098926

35. Cheng W, Finnie I (1985) A method for measurement of axisymmetric axial residual stresses in circumferentially welded thinwalled cylinders. J Eng Mater Technol 107(3):181-185. https:// doi.org/10.1115/1.3225799

36. Lloyd RR (2013) Evaluation of 6061 Al Alloy Mechanical Properties of Fuel Plate Cladding: HIP-Bonded Fuel Plates TEV-1758 R0. Idaho National Lab (INL), Idaho Falls, ID (United States). https://doi.org/10.2172/1547065 (Report INL-MIS-18-50073-Rev000)

37. Prime MB, Pagliaro P (2006) Uncertainty, model error, and improving the accuracy of residual stress inverse solutions. In: Proceedings of the 2006 SEM Annual Conference and Exposition on Experimental and Applied Mechanics, St. Louis, Missouri, pp 479-488

38. Woolstenhulme NE, Taylor SC, Moore GA, Sterbentz DM (2012) Non-Destructive Examination of Fuel Plates for the RERTR Fuel Development Experiments. Idaho National Laboratory (INL), Idaho. https://doi.org/10.2172/1058072 (Report INL/ EXT-12-27225)

39. Finnie S, Cheng W, Finnie I, Drezet JM, Gremaud M (2003) The computation and measurement of residual stresses in laser deposited layers. J Eng Mater Technol 125(3):302-308. https://doi.org/ $10.1115 / 1.1584493$

40. Ersoy N, Vardar O (2000) Measurement of residual stresses in layered composites by compliance method. J Compos Mater 34(7):575-598. https://doi.org/10.1177/002199830003400703

41. Salehi SD, Shokrieh MM (2019) Residual stress measurement using the slitting method via a combination of eigenstrain, regularization and series truncation techniques. Int J Mech Sci 152:558-567. https://doi.org/10.1016/j.ijmecsci.2019.01.011

42. Smit TC, Reid RG (2018) Residual Stress Measurement in Composite Laminates Using Incremental Hole-Drilling with Power Series. Exp Mech 58(8):1221-1235. https://doi.org/10.1007/ s11340-018-0403-6

43. Smit TC, Reid RG (2020) Tikhonov regularization with Incremental Hole-Drilling and the Integral Method in Cross-Ply Composite Laminates. Exp Mech 60(8):1135-1148. https://doi.org/10.1007/ s11340-020-00629-x

44. Schajer GS, Prime MB (2006) Use of Inverse Solutions for Residual Stress Measurements. J Eng Mater Technol 128:375-382. https://doi.org/10.1115/1.2204952

45. Phillips AM, Larsen ED, Benefiel BC, Prime MB, Cole JI, Davies KB (2018) Residual Stress System Development. Idaho National Laboratory, Idaho (Report INL/EXT-18-51764)

46. Prime MB, Crane DL (2014) Slitting Method Measurement of Residual Stress Profiles, Including Stress Discontinuities, in Layered Specimens. In: Rossi M, Sasso M, Connesson N et al (eds) 
Residual Stress, Thermomechanics \& Infrared Imaging, Hybrid Techniques and Inverse Problems, vol 8. Conference Proceedings of the Society for Experimental Mechanics Series. Springer International Publishing, Cham, pp 93-102. https://doi.org/10.1007/ 978-3-319-00876-9_12

47. Schajer GS (1988) Measurement of non-uniform residual-stresses using the hole-drilling method 1 Stress calculation procedures. J Eng Mater Technol 110(4):338-343. https://doi.org/10.1115/1. 3226059

48. Prime MB, Hill MR (2006) Uncertainty, Model Error, and Order Selection for Series-Expanded, Residual-Stress Inverse Solutions. J Eng Mater Technol 128(2):175-185. https://doi.org/10.1115/1. 2172278

49. Olson MD, DeWald AT, Hill MR (2020) An Uncertainty Estimator for Slitting Method Residual Stress Measurements Including the Influence of Regularization. Exp Mech 60(1):65-79. https:// doi.org/10.1007/s11340-019-00535-x

50. Olson MD, DeWald AT, Hill MR (2020) Precision of Hole-Drilling Residual Stress Depth Profile Measurements and an Updated Uncertainty Estimator. Exp Mech 61(3):549-564. https://doi.org/10.1007/ s11340-020-00679-1

51. Chen MJ, Aquino W, Walsh TF, Reu PL, Johnson KL, Rouse JW, Jared BH, Bishop JE (2020) A Generalized Stress Inversion Approach With Application to Residual Stress Estimation. J Appl Mech 87(11):111007. https://doi.org/10.1115/1.4048097

52. Lee MJ, Hill MR (2007) Effect of strain gage length when determining residual stress by slitting. J Eng Mater Technol 129(1):143-150. https://doi.org/10.1115/1.2400263

53. Rankin JE, Hill MR, Hackel LA (2003) The effects of process variations on residual stress in laser peened $7049 \mathrm{~T} 73$ aluminum alloy. Mater Sci Eng A 349(1-2):279-291. https://doi.org/10. 1016/S0921-5093(02)00811-0

54. Aydiner CC, Prime MB (2013) Three-Dimensional Constraint Effects on the Slitting Method for Measuring Residual Stress. J Eng Mater Technol 135:031006. https://doi.org/10.1115/1.4023849

55. Brown DW, Alexander DJ, Clarke KD, Clausen B, Okuniewski MA, Sisneros TA (2013) Elastic properties of rolled uranium10wt.\% molybdenum nuclear fuel foils. Scr Mater 69(9):666-669. https://doi.org/10.1016/j.scriptamat.2013.07.025

56. Simulia Abaqus (2020) Dassault Systèmes, Vélizy-Villacoublay, France

57. Behnam K, Heydarian S, Mahmoudi AH (2015) Stress Variations Effect on the Accuracy of Slitting Method for Measuring Residual Stresses. Int J Eng 28(9):1368-1374

58. Montay G, Sicot O, Maras A, Rouhaud E, François M (2009) Two Dimensions Residual Stresses Analysis Through Incremental Groove Machining Combined with Electronic Speckle Pattern Interferometry. Exp Mech 49(4):459-469. https://doi.org/10.1007/ s11340-008-9151-3

59. Crapps J, Clarke K, Katz J, Alexander DJ, Aikin B, Vargas VD, Montalvo JD, Dombrowski DE, Mihaila B (2013) Development of the hot isostatic press manufacturing process for monolithic nuclear fuel. Nucl Eng Des 254:43-52. https://doi.org/10.1016/j. nucengdes.2012.09.002

60. Rabin B, Meyer M, Cole J, Glagolenko I, Hofman G, Jones W, Jue J, Keiser D Jr, Kim Y, Miller C (2017) Preliminary Report on U-Mo Monolithic Fuel for Research Reactors. Idaho National Laboratory, Idaho Falls, USA (Report INL/EXT-17-40975)

61. Burkes DE, Prabhakaran R, Hartmann T, Jue J-F, Rice FJ (2010) Properties of DU-10 wt\% Mo alloys subjected to various postrolling heat treatments. Nucl Eng Des 240(6):1332-1339. https:// doi.org/10.1016/j.nucengdes.2010.02.008

62. Jue J-F, Keiser DD, Breckenridge CR, Moore GA, Meyer MK (2014) Microstructural characteristics of HIP-bonded monolithic nuclear fuels with a diffusion barrier. J Nucl Mater 448(1):250 258. https://doi.org/10.1016/j.jnucmat.2014.02.004

63. Ajantiwalay T, Smith C, Keiser DD, Aitkaliyeva A (2020) A critical review of the microstructure of U-Mo fuels. J Nucl Mater 540:152386. https://doi.org/10.1016/j.jnucmat.2020.152386

64. Alexander DJ, Clarke KD, Liu C, Lovato ML (2011) Tensile Properties of 6061 Aluminum Alloy Materials. Los Alamos National Laboratory, New Mexico (Report LA-UR-11-06707)

65. Lloyd RR (2013) Evaluation of 6061 Al Alloy Mechanical Properties of Fuel Plate Cladding: HIP-Bonded Fuel Plates TEV-1758 R0. Idaho National Laboratory, Idaho Falls. https://doi.org/10. 2172/1547065.IDReportINL-MIS-18-50073-Revision-0

66. Totten GE (2016) Heat Treating of Nonferrous Alloys, vol 4E, vol 4E. ASM International, Almere. https://doi.org/10.31399/asm.hb. v04e.9781627081696

67. Kim HK, Coules HE, Pavier MJ, Shterenlikht A (2015) Measurement of Highly Non-Uniform Residual Stress Fields with Reduced Plastic Error. Exp Mech 55(7):1211-1224. https://doi.org/10. 1007/s11340-015-0025-1

68. Schuster S, Steinzig M, Gibmeier J (2017) Incremental Hole Drilling for Residual Stress Analysis of Thin Walled Components with Regard to Plasticity Effects. Exp Mech 57(9):1457-1467. https:// doi.org/10.1007/s11340-017-0318-7

69. Muránsky O, Hamelin CJ, Hosseinzadeh F, Prime MB (2016) Mitigating cutting-induced plasticity in the contour method Part 2: Numerical analysis. Int J Solids Struct 94:254-262. https://doi. org/10.1016/j.ijsolstr.2015.12.033

70. Prime MB (2010) Plasticity effects in incremental slitting measurement of residual stresses. Eng Fract Mech 77(10):1552-1566. https://doi.org/10.1016/j.engfracmech.2010.04.031

71. Beghini M, Bertini L (1998) Recent advances in the hole drilling method for residual stress measurement. J Mater Eng Perform 7(2):163-172

Publisher's Note Springer Nature remains neutral with regard to jurisdictional claims in published maps and institutional affiliations. 